\title{
Portal Vein Thrombosis
}

\author{
Yogesh K. Chawla, Vijay Bodh \\ Department of Hepatology, Post Graduate Institute of Medical Education and Research, Chandigarh 160012, India
}

\begin{abstract}
Portal vein thrombosis is an important cause of portal hypertension. PVT occurs in association with cirrhosis or as a result of malignant invasion by hepatocellular carcinoma or even in the absence of associated liver disease. With the current research into its genesis, majority now have an underlying prothrombotic state detectable. Endothelial activation and stagnant portal blood flow also contribute to formation of the thrombus. Acute non-cirrhotic PVT, chronic PVT (EHPVO), and portal vein thrombosis in cirrhosis are the three main variants of portal vein thrombosis with varying etiological factors and variability in presentation and management. Procoagulant state should be actively investigated. Anticoagulation is the mainstay of therapy for acute non-cirrhotic PVT, with supporting evidence for its use in cirrhotic population as well. Chronic PVT (EHPVO) on the other hand requires the management of portal hypertension as such and with role for anticoagulation in the setting of underlying prothrombotic state, however data is awaited in those with no underlying prothrombotic states. TIPS and liver transplant may be feasible even in the setting of PVT however proper selection of candidates and type of surgery is warranted. Thrombolysis and thrombectomy have some role. TARE is a new modality for management of HCC with portal vein invasion. (J CLIN EXP Hepatol 2015;5:22-40)
\end{abstract}

$\mathrm{P}$ ortal vein thrombosis (PVT) refers to thrombosis that develops in the trunk of the portal vein including its right and left intrahepatic branches and may even extend to the splenic or superior mesenteric veins or towards the liver involving intrahepatic portal branches. PVT occurs either in association with cirrhosis

Keywords: PVT, prothrombotic, acute and chronic, imaging, anticoagulation

Received: 15.4.2014; Accepted: 31.12.2014; Available online 7.1.2015

Address for correspondence: Yogesh K. Chawla, Professor and Head, Department of Hepatology, Post Graduate Institute of Medical Education and Research, Chandigarh 160012, India. Tel.: +91 172 2756344x6335; fax: +91 1722744401

E-mail:ykchawla@gmail.com

Abbreviations: ACLA: anti-cardiolipin antibody; AFP: alpha feto protein; BCS: Budd-Chiari syndrome; CDUS: color doppler ultrasonography; CT: computed tomography; CTP: Child Turcotte Pugh; EHPVO: extra hepatic portal venous obstruction; EST: endoscopic sclerotherapy; HCC: hepatocellular carcinoma; HVPG: hepatic venous pressure gradient; IGF-1: insulin like growth factor-1; IGFBP-3: insulin like growth factor binding protein-3; INR: international normalized ratio; JAK-2: Janus kinase 2; LA: lupus anticoagulant; LMWH: low molecular weight heparin; MELD: model for end stage liver disease; MPD: myeloproliferative disorder; MRI: magnetic resonance imaging; MTHFR: methylenetetrahydrofolate reductase; MVT: mesenteric vein thrombosis; OCPs: oral contraceptive pills; PAI-1 4G-4G: plasminogen activator inhibitor type 1- 4G/4G genotype; PNH: paroxysmal nocturnal hemoglobinuria; PV: portal vein; PVT: portal vein thrombosis; PWUS: Pulsed Wave ultrasonography; SMA: superior mesenteric artery; SMV: superior mesenteric vein; RFA: radio frequency ablation; rtPA: recombinant tissue plasminogen activator; TAFI: thrombin activatable fibrinolysis inhibitor; TARE: Trans arterial radioembolization; TB: tuberculosis; TIPS: transjugular intrahepatic portosystemic shunt; UFH: unfractionated heparin

http://dx.doi.org/10.1016/j.jceh.2014.12.008 or malignancy of liver or may occur without an associated liver disease. The terminology of Extra Hepatic Portal Venous Obstruction (EHPVO) refers to the development of portal cavernoma in the absence of associated liver disease. EHPVO should be considered as a separate entity. Portal vein thrombosis is an important cause of noncirrhotic prehepatic portal hypertension all over the world.

Balfour and Stewart described the first case of PVT in 1868 in a patient with ascites, splenomegaly and variceal dilation. ${ }^{1}$ Since then portal vein thrombosis has been well studied and described in patients with or without cirrhosis. The prevalence of PVT in compensated liver disease has been reported to be $0.6-16 \%, 15 \%(5-26 \%)$ in patients awaiting liver transplantation and upto $36 \%$ in explanted liver on histopathology. ${ }^{2-4}$ PVT is seen in upto $35 \%$ of cirrhotic patients with hepatocellular carcinoma. $^{5,6}$ The lifetime risk of PVT in general population is reported to be $1 \%{ }^{7}$ This review article is mainly focused on portal vein thrombosis in non-cirrhotic population-acute (recent thrombosis), chronic long standing (extrahepatic portal venous obstruction) and in patients with cirrhosis.

\section{ETIOLOGY}

The pathophysiology of portal vein thrombosis encompasses one or more features of Virchow's triad, viz., reduced portal blood flow, a hypercoagulable state or vascular endothelial injury as in Figure 1 . Based on the three pathogenetic mechanisms, the etiological risk factors for non-cirrhotic and cirrhotic PVT will be discussed separately. 


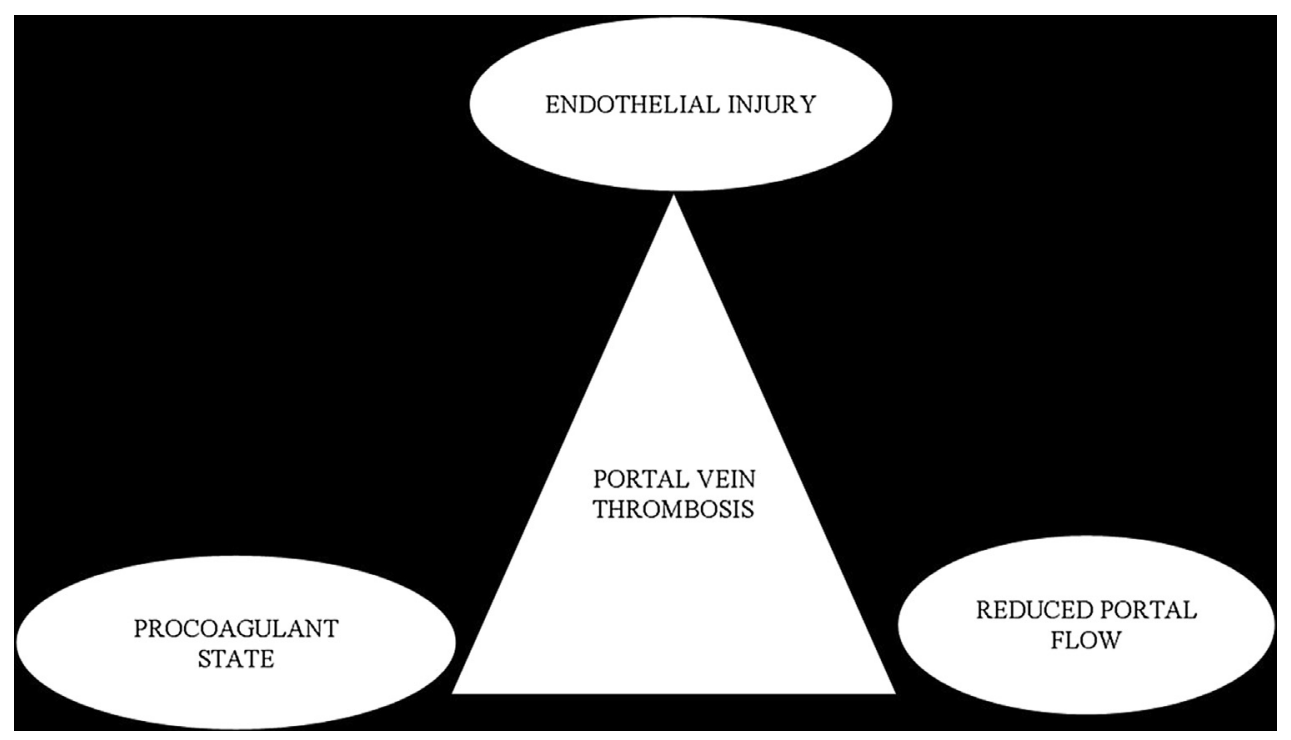

Figure 1 Virchow's triad for portal vein thrombosis.

\section{Acute Non-cirrhotic Portal Vein Thrombosis \\ Procoagulant State}

Various prothrombotic states leading to portal vein thrombosis have been identified (Table 1). Significant advances over the last decade have shown the earlier labeled idiopathic cases now being associated with thrombophilic conditions which are identified in approximately $60 \%$ of patients and an additional local predisposing factor in $30-40 \%$ of cases. In upto $80 \%$ cases the underlying cause is identified when rigorously searched for. ${ }^{8-13}$ In some cases multiple prothrombotic factors may be associated in the development of PVT. ${ }^{14-16}$ In one study one or more risk factors namely prothrombotic state or abdominal inflammation was present in $87 \%$ of patients. ${ }^{17}$ Amongst the thrombophilic states, primary myeloproliferative disorders (MPD) are common in $30.5 \%$. Occult MPD as a cause of PVT is seen in $16.7 \%$ and classical MPD in $13.8 \%{ }^{18}$ The diagnosis of myeloproliferative disorders as a cause of PVT has increased by $20 \%$ with the identification of Janus kinase 2 (JAK 2) V617F

Table 1 Prothrombotic Causes of Portal Vein Thrombosis.

Inherited prothrombotic disorders
$\square$ Factor V Leiden mutation
$\square$ Factor II gene mutation
$\square$ Protein C deficiency
$\square$ Protein S deficiency
$\square$ Antithrombin III deficiency
Acquired thrombophilic disorders
$\square$ Primary myeloproliferative disorders
$\square$ Paroxysmal nocturnal hemoglobinemia
$\square$ Antiphospholipid syndrome
$\square$ Hyperhomocysteinemia
$\square$ Increased factor VIII levels
$\square$ Thrombin activatable fibrinolysis inhibitor gene (TAFI)

gene mutation. The presence of JAK 2 mutation is seen in around $17-35 \%$ patients of PVT. It is now recommended by the WHO as a major diagnostic criterion for the diagnosis of MPD. ${ }^{19-21}$ PVT is a manifestation of myeloproliferative disease in $22-48 \%$ of patients. In the West, latent MPD has been reported in 58\% of patients with idiopathic PVT and 51\% of these developed overt MPD on follow up. ${ }^{22}$ A recent study reported PVT as the first manifestation of MPD in $70 \%$ (31 of 44 patients). ${ }^{23}$ Meta analysis of myeloproliferative disorders in PVT showed that the mean prevalence of MPD is $31.5 \%(95 \%$ CI $25.1-38.8 \%$ ) and JAK2 mutation is $27.7 \%$ (95\% ci 20.8 35.8). JAK2 and MPD both are more frequent in BCS than PVT. JAK2 mutation in splanchnic venous thrombosis without MPD features was able to identify MPD in $15.4 \%$ of PVT patients. $^{24}$ In Asians, the prevalence of JAK2 mutation is $24-26.6 \%$ in non-cirrhotic non-malignant PVT versus $1.4 \%$ in cirrhosis with PVT. ${ }^{25,26}$ An Indian study reported $14 \%$ prevalence of JAK2 mutation in portal vein thrombosis out of 58 patients of intraabdominal venous thrombosis (which included portal vein thrombosis and Budd-Chiari syndrome). ${ }^{27}$ Other prothrombotic conditions that cause PVT include paroxysmal nocturnal hemoglobinuria (PNH), antiphospholipid syndrome, hyperhomocysteinemia, inherited prothrombotic disorders such as protein C (in 0-9.1\%), S (0.9-30\%) and antithrombin III deficiencies (0-4.5\%) and less frequently factor $\mathrm{V}$ Leiden mutation (1.3-7.6\%), factor II mutation (G20210A in 0-22\%) and methylenetetrahydrofolate reductase (MTHFR) gene mutation. ${ }^{9-11}$ These inherited disorders may be a secondary phenomenon rather than primary, since they are produced from the liver and may be affected in parenchymal liver disease. They may ultimately be confirmed by investigating first degree relatives. ${ }^{9,12,28}$ Recently mutation in thrombin activatable 
fibrinolysis inhibitor (TAFI) gene and high levels of factor VIII have been shown to be associated with a risk of PVT. ${ }^{29,30}$ A recent data on thrombophilia by D Amico et al showed that myeloproliferative disorders were the most common cause in PVT patients and thrombophilia work up in the PVT patients revealed PAI-1 4G-4G (plasminogen activator inhibitor type 1- 4G/4G genotype) as the most common cause (55.5\%) followed by MTHFR mutation (28.6\%), factor V Leiden mutation $(7.4 \%)$ and prothrombin gene mutation (7.4\%). Atleast one thrombophilic state was present in $81.5 \%$ and more than one hypercoagulable state was present in $18.5 \%{ }^{31}$ The meta analysis on thrombophilia in portal venous system thrombosis showed the prevalence of antithrombin III deficiency in $3.9 \%$, protein $\mathrm{C}$ deficiency in $5.6 \%$ and protein $\mathrm{S}$ deficiency in $2.6 \%$ with Odds ratio of $8.89,17.63$ and 8.00 respectively. ${ }^{32}$ Indian data on hypercoagulable states in portal vein thrombosis reveal that the inherited thrombophilia is infrequent in the Indian population. Protein $\mathrm{C}$ deficiency is seen in $8-9 \%$, protein $S$ deficiency in 3-4\%, factor $\mathrm{V}$ Leiden mutation in 3-6\% and antiphospholipid antibody in $18-23 \% .{ }^{11,33-35}$ Antithrombin III deficiency and prothrombin gene mutation are however uncommon. However another study from India of 26 PVT patients showed the presence of protein C deficiency in 12, protein $S$ deficiency in 9 , antithrombin III deficiency in 8 patients, ACLA in 3 and LA in 4 patients. No prothrombin gene mutation and PNH states were seen in this study. ${ }^{36}$ High factor VIII levels have also been shown to be associated with portal vein thrombosis in Indian patients. ${ }^{37}$ Heterozygous MTHFR has been reported in 21\% of PVT patients and hyperhomocysteinemia in $7.6 \%$ while homozygous MTHFR has not been seen. ${ }^{11}$ A strong link of Bacteroides fragillus infection with PVT has also been demonstrated possibly due to transient development of anti-cardiolipin antibodies. ${ }^{38}$ Other conditions that are associated with PVT are use of oral contraceptives, cytomegalovirus infection, ${ }^{39}$ pregnancy, chronic inflammatory diseases and malignancies in the background of the above prothrombotic causes. $^{8}$

\section{Vascular Endothelial Injury}

Local risk factors may also lead to thrombosis via endothelial activation of prothrombotic factors as a result of various intra-abdominal inflammatory diseases. The intra-abdominal inflammatory conditions leading to sepsis that cause PVT include pancreatitis, cholecystitis, cholangitis, appendicitis, liver abscess and local injury to portal venous axis following splenectomy including laparoscopic splenectomy, laparoscopic colectomy, abdominal trauma, portocaval shunts $\&$ other intra-abdominal surgical procedures in association with the above acquired or inherited prothrombotic conditions. ${ }^{40-44}$ A recent study of 102 patients with non-cirrhotic non-malignant acute PVT showed the presence of local factors as a cause for thrombosis in upto $21 \%$ and acute pancreatitis as the most common cause followed by cholecystitis or cholangitis and liver abscess. ${ }^{45}$ PVT may also occur after ablative therapy for HCC and fine needle aspiration of pancreatic mass. ${ }^{46-48}$ PVT sometimes occurs after liver transplantation at the anastomotic site due to donor/ recipient portal vein diameter mismatch. ${ }^{49,50}$ Transient PVT has been reported in $23 \%$ of patients with acute pancreatitis and $57 \%$ in those with pancreatic necrosis. ${ }^{51}$ PVT may also occur with Budd-Chiari syndrome mainly due to stagnant portal venous flow and an underlying prothrombotic state. ${ }^{52}$ Recently thrombosis of the portal and mesenteric veins has been described presenting as a medical emergency in troops posted at high altitudes in India. ${ }^{53}$ In the Asian Pacific region PVT in children has been attributed to omphalitis, neonatal umbilical sepsis overt or unrecognized and umbilical vein cannulation. ${ }^{54}$ However, a study has shown that although umbilical venous catheter associated thrombosis is common spontaneous resolution occurs in most cases. ${ }^{55}$ Therapeutic contralateral portal vein embolization before major hepatic resection is practiced at a few centers, where the future remnant liver volume is likely to be less than $30 \%$ of total liver. With successful therapeutic PVT of the contralateral site, there is hypertrophy of functional residual liver by $47 \%$ after $4-8$ weeks, which helps in prevention of liver failure. $^{56}$

\section{Reduced Portal Blood Flow}

Direct vascular invasion by hepatocellular carcinoma and cholangiocarcinoma leads to malignant portal vein obstruction. Malignancy as a cause of PVT is seen in 21$24 \%$. Apart from vascular invasion, compression by tumor mass or hypercoagulable state are the mechanisms involved. Portal vein compression by lymph node (TB, lymphoma) also contributes to PVT by reducing portal blood flow.

\section{Chronic Portal Vein Thrombosis (Extra Hepatic Portal Venous Obstruction)}

EHPVO in children

\section{Infection}

It is hypothesized that EHPVO in children has initial component of phlebosclerosis, with thrombosis as a secondary event, ${ }^{57}$ due to infection or a primary thrombotic disorder. Omphalitis, neonatal umbilical sepsis, umbilical vein cannulation, repeated abdominal infections, sepsis, abdominal surgery and trauma can also result in EHPVO. ${ }^{54}$

\section{Congenital Anomaly}

Congenital anomalies of left and right vitelline veins from which the portal vein develops can result in obstruction and congenital defects of other systems have also been reported. $^{58}$ 


\section{Prothrombotic State}

The frequency of prothrombotic disorders has been found to be variable in children. ${ }^{11,59}$

\section{Idiopathic}

The cause of EHPVO may remain obscure in $50 \%$ of patients.

\section{EHPVO in adults}

\section{Prothrombotic Disorders}

Prothrombotic states are more common in adults. ${ }^{11}$ In the West, latent myeloproliferative disorder has been reported in $58 \%$ patients with EHPVO of unknown etiology, and $57 \%$ of these go on to develop an overt myeloproliferative disorder during follow-up. ${ }^{22}$ Other studies have not corroborated these findings. One study found only methyl tetrahydrofolate reductase mutation to be higher in EHPVO patients than deep vein thrombosis patients among the prothrombotic states. ${ }^{12}$

\section{Infection and Surgery}

Intra-abdominal sepsis and abdominal surgery contribute to EHPVO.

\section{Pregnancy and Oral Contraceptives}

Both pregnancy and OCPs in the presence of a prothrombotic disorder can result in EHPVO.

\section{Portal Vein Thrombosis in Cirrhosis}

\section{Procoagulant State}

Cirrhosis is no longer considered a hypocoagulable state. In fact the procoagulant and anticoagulant factors are in a state of balance in cirrhosis with no increased bleeding risk. Instead, increased factor VIII levels, reduced albumin tilt the balance towards hypercoagulability in cirrhosis. In patients with cirrhosis, G20210A mutation of prothrombin has a prevalence of $21.4-29 \%$ with Odds ratio of 5.9 for development of PVT. Mutation of prothrombin gene was found to be the only thrombophilic condition associated with PVT in 701 cirrhotics. ${ }^{5}$ Thrombophilic state is detected in $69.5 \%$ patients of cirrhosis with PVT. The frequencies of factor $V$ Leiden mutation, prothrombin gene mutation, and homozygous MTHFR C677T in cirrhotics with PVT were detected in 13\%, 34.8\% and 43.5\% respectively. ${ }^{60}$ Another study on PVT in cirrhotics concluded that prothrombotic mutations by themselves are not causative of PVT, but sclerotherapy and previous abdominal surgery favors development of PVT in $2 / 3 \mathrm{rd}$ of cases but is elusive in others. ${ }^{61}$ The frequency of Factor $\mathrm{V}$ Leiden mutation (29\%) and prothrombin gene mutation (29\%) are more frequent in cirrhosis with PVT compared to cirrhosis without PVT, non-cirrhotics with PVT and healthy controls. ${ }^{62}$

\section{Reduced Portal Blood Flow}

In cirrhosis, portal hemodynamics play an important role in the development of portal vein thrombosis. A study by Zocco et al showed portal flow velocity of less than $15 \mathrm{~cm} / \mathrm{s}$ on Doppler ultrasound as a predictive factor for the development of portal vein thrombosis with a risk of $47.8 \%$ when compared to $2 \%$ risk with a flow of more than $15 \mathrm{~cm} / \mathrm{s} .^{63}$ The parenchymal architectural distortion in cirrhosis and altered vascular reactivity results in increased intrahepatic vascular resistance and reduction in portal blood flow. The development of portosystemic collateral circulation and splanchnic vasodilatation on venous side also adds to stagnation of the portal blood flow leading to PVT. A recent study has also shown that in patients with PVT, the largest collateral vessel blood flow was an independent predictor of PVT. The blood flow velocity in the largest collateral $(>10 \mathrm{~cm} / \mathrm{s})$ and flow volume $(>400 \mathrm{ml} / \mathrm{min}$ ) were associated with increased incidence of portal vein thrombosis in virus related cirrhosis. ${ }^{64}$

\section{Vascular Endothelial Injury}

Endoscopic therapy of bleeding varices also leads to direct endothelial damage or procedure related bacteremia leading to development of thrombosis. PVT has been described following endoscopic sclerotherapy in patients with cirrhosis in association with these thrombophilic conditions. ${ }^{65}$ Endotoxemia in cirrhosis may increase the risk of PVT in cirrhosis.

\section{PRESENTATION}

Clinically PVT may be acute or chronic. Although no time frame exists, to distinguish acute from chronic PVT, it is usually considered acute if symptoms developed $<60$ days prior to hospital assessment. ${ }^{66}$ This may not hold true always as patients with chronic PVT may first present with upper GI bleeding. An easy way to differentiate acute PVT from chronic PVT is the absence or insignificant portoportal collaterals on imaging and no evidence of portal hypertension including splenomegaly and esophageal varices. The proportion of patients who develop chronic PVT from acute is known for those who develop symptomatic PVT recognized early however it is unclear for those who develop asymptomatic PVT.

\section{Acute Non-cirrhotic Portal Vein Thrombosis}

In acute PVT there is a sudden formation of thrombosis within the portal vein that leads to a complete or partial obstruction of the portal vein. Acute PVT in non-cirrhotic non-malignant PVT usually presents with abdominal pain (91\%), fever (53\%), ascites (38\%) which is small volume ascites (detectable only on imaging in $33 \%$ and clinical ascites in $5 \%) .{ }^{45}$ Splenomegaly is seen in $37 \%$ patients and $40 \%$ of 
which have an underlying myeloproliferative disorder. In the remaining $63 \%$ patients without splenomegaly, myeloproliferative disorder is detected in only $5 \%$ patients. ${ }^{45}$ Involvement of superior mesenteric vein and the mesenteric venous arches may lead to intestinal ischemia, bowel infarction and ileus. Patients may then present with hematochezia, rebound tenderness, fever and ascites. Bowel infarction is an important cause of mortality in patients with thrombosis of portal venous system. ${ }^{40}$ Partial obstruction of portal vein may be associated with lesser symptoms. Acute development of ascites, although rare, may also be seen which is usually mild and transient due to intestinal venous congestion. The natural history of acute PVT is usually uncertain and modified by medical intervention.

\section{Chronic Portal Vein Thrombosis (Extra Hepatic Portal Venous Obstruction)}

Patients with chronic PVT or classically referred to as EHPVO present with portal hypertension related complications like a well tolerated variceal bleed, splenomegaly, anemia and thrombocytopenia or may be asymptomatic with incidental detection following an imaging procedure.

The most common presentation in children is recurrent upper gastrointestinal bleeding. ${ }^{67,68}$ Bleeding usually occurs in the first or second decade of life. The bleed is well tolerated due to underlying normal functioning liver. Transient ascites is seen in one fifth of children following the episode of bleed. ${ }^{69}$ About $10 \%$ of children present with isolated splenomegaly. ${ }^{70}$ Splenomegaly is almost universal and may be symptomatic with left upper abdominal discomfort (due to massive splenomegaly) or as pain (due to splenic infarcts) or sometimes as symptomatic hypersplenism. Hypersplenism is seen in upto one third of patients and is usually asymptomatic. Splenomegaly may transiently reduce during episodes of acute variceal bleed. Growth retardation may be seen in upto $50 \%$ of children due to possibly impaired synthesis of growth factors, insulin like growth factor (IGF-1) and insulin like growth factor binding protein-3 (IGFBP-3) and increased levels of growth hormone leading to growth hormone resistance, increased frequency of bleed and malabsorption due to portal hypertensive enteropathy. ${ }^{71,72}$ Mild cognitive and psychomotor dysfunction has also been reported in children. Ectopic varices at sites like duodenum, anorectum, colon or gallbladder are significantly more common in chronic PVT than in patients' with cirrhosis. $^{73,74}$ Ascites and encephalopathy are not common and usually transient precipitated by gastrointestinal bleed. A spurt in growth after shunt surgery in children has been observed. ${ }^{75}$ Another study however did not show any growth impairment in children with PVT. ${ }^{76}$
Chronic PVT in adults presents with recurrent upper gastrointestinal bleed like children. Bleed may occur from esophago-gastric varices or ectopic varices in duodenum or elsewhere. Transient ascites may occur following bleed. Overt hepatic encephalopathy is rare but minimal hepatic encephalopathy may be seen in $50 \%$ of patients due to portosystemic shunting. Hypersplenism may rarely be symptomatic and patients can also develop portal biliopathy. ${ }^{77}$ Other rare clinical manifestations include obstructive jaundice, cholangitis and even choledocholithasis late in the natural course of the disease due to pseudosclerosing cholangitis or portal hypertensive biliopathy. ${ }^{78-83}$

\section{Portal Vein Thrombosis in Cirrhosis}

In a study of 701 cirrhotics, development of portal vein thrombosis occurred in $79(11.2 \%)$ patients. Majority of patients were in child B and C. PVT was asymptomatic in $43 \%$ and symptomatic in $57 \%$. Symptoms included gastrointestinal bleed in 31 (39.2\%) patients (18 were variceal bleed and 13 were portal hypertensive gastropathy related) and abdominal pain in 14 (17.7\%). Ten patients (70\%) with abdominal pain had intestinal infarction. ${ }^{5}$ Mesenteric venous involvement was never asymptomatic and lead to intestinal ischemia or infarction. Another study which included cirrhosis and cancer both $(\mathrm{n}=19)$, abdominalia (abdominal pain, loss of appetite, nausea, vomiting, diarrhea) was seen in $63 \%$, bleeding (hematemesis, melena or rectal) in $58 \%$, splenomegaly in $63 \%$, fever in $37 \%$, ascites in $32 \%$, and weight loss in $16 \%$ patients. ${ }^{17}$

\section{DIAGNOSIS}

\section{Liver Function}

The liver functions are normal or near normal except if PVT occurs in a patient with cirrhosis. Prothrombin levels and other coagulation factors may be decreased while Ddimer is usually increased. ${ }^{18,84}$ Patients with portal hypertensive biliopathy may show a rise in alkaline phosphatase. Liver grossly is normal in PVT, but may show atrophy and regenerative nodular hyperplasia, related to apoptosis and compensatory arterial vasodilation in chronic PVT. ${ }^{85-87}$ Liver function derangement may be seen in EHPVO in the form of ascites, prothrombin time prolongation and low serum albumin in patients with prolonged portal hypertension. ${ }^{69}$

\section{Ultrasound}

Ultrasound is the investigation of choice. It shows solid isoechoic or hypoechoic material within portal vein either filling the lumen partially or complete. ${ }^{88}$ It is the least expensive method but sensitivity and specificity is affected by interpatient variability and expertise of the given radiologist. ${ }^{89}$ Overall the sensitivity and specificity of ultrasound 
for detecting portal vein thrombosis ranges from 80 to $100 \%$ with an accuracy of $88-98 \%$. Demonstration of a portal cavernoma (multiple tortuous small vessels replacing the portal vein) is suggestive of chronic PVT, and is usually associated with splenomegaly and collaterals in relation to portal venous system. Color Doppler ultrasonography (CDUS) and Pulsed Wave ultrasonography (PWUS) demonstrated the absence or reduced flow in portal vein. The diagnostic sensitivity and specificity for Color Doppler Ultrasound (CDUS) in detecting portal vein thrombosis varies from $66 \%$ to $100 \% .^{90,91}$ Contrast enhanced ultrasound (CDUS) is another modality that has been found to be superior to ultrasound in demonstrating the presence or absence of flow and is more reliable in patients with extremely low portal vein velocity. Endoscopic ultrasound has also been reported to be a sensitive $(81 \%)$ and specific $(93 \%)$ test to diagnose portal vein thrombosis. ${ }^{92-94}$ Gallbladder varices on ultrasound have been seen in $12-30 \%$ of adults with chronic PVT. ${ }^{95}$

\section{Computed Tomography and Magnetic Resonance Imaging}

CT and MRI provide additional information such as extension of thrombus, evidence of bowel infarction and status of adjacent organs. On non-contrast enhanced CT, portal vein thrombus is generally seen to be isodense to adjacent soft tissue, but may be hyperdense if it occurred within a month. ${ }^{96}$ Following intravenous administration of iodinated contrast on CT, a bland thrombus is seen as a low density, non-enhancing defect within portal veins, while a tumor thrombus enhances following contrast administration. Moreover dynamic CT shows a filling defect partially or totally occluding the vessel lumen with rim enhancement of the vessel wall. ${ }^{97}$ Certain other features of malignant portal vein obstruction include expansive effect (portal vein enlargement due to the mass forming thrombus), disruption of the vessel wall and intra thrombus arterial neovascularization. The sensitivity and specificity of MRI for detecting main PVT are $100 \%$ and $98 \%$ respectively in patients undergoing liver transplantation, the discordance being due to a decreased caliber of main portal vein that may be interpreted as recanalised chronic thrombus. ${ }^{98}$ MR portography has been shown to be superior to color Doppler US in detecting partial thrombosis, and occlusion of the main portal venous vessels. It also identifies portosplenic collaterals and portal venous vessels more adequately that cannot be visualized on color Doppler. MR portographic demonstration of portal vein occlusion may be reported as normal on CDUS and vice versa due to slow flow velocity in portal vein. ${ }^{99}$ True fast imaging with steady state precession (true FISP) with MRI has been shown to be a useful adjunct to contrast enhanced MR angiography in severely debilitated patients, where respiratory motion may degrade the images or when the use of contrast medium is not possible due to poor venous access. ${ }^{100}$ MR portography is valuable in determining the resectability of neoplasm involving the portal venous system ${ }^{101}$ and follow-up after therapeutic procedures ${ }^{102}$ including surgical splenorenal and mesocaval shunts. MR angiography has precluded the use of effective, but more invasive techniques like carbon dioxide portography or intraarterial digital subtraction angiography. ${ }^{103,104}$ PET CT has been shown to be helpful in discriminating between benign and malignant portal vein obstruction. ${ }^{105}$

\section{Splenoportovenography}

This investigation involves injecting dye in the splenic pulp and visualizing the splenoportal venous axis which helps not only in diagnosing PVT but also identifying the patency of splenoportal axis for future shunt surgery. Of the cases done by us in the preUS/CT/MRI era, it proved to be a safe procedure which also helped detecting the portal pressure and assessing the effect of drugs, since HVPG is fallacious in PVT. ${ }^{106}$ With the advent of newer non-invasive techniques splenoportovenography is now an obsolete procedure.

\section{Endoscopy}

It is important to have endoscopy in patients with PVT as portal hypertensive gastropathy is more often present in the acute PVT with cancer or cirrhosis, while large esophageal varices are present more often in patients with chronic PVT. ${ }^{17}$ In chronic PVT gastric varices are seen in upto $40 \%$ of patients. ${ }^{107}$ Ectopic varices are more often seen in chronic PVT compared with other causes of portal hypertension. Rectal varices are seen in $80 \%$ of patients. Large varices are an independent risk factor for bleeding in patients with PVT however despite large varices, with red signs, the frequency of bleeding in patients with PVT is $0.25 \%$ over 2 years which appears to be far less than in cirrhotics with similar variceal characteristics $(20-30 \%$ bleeding risk over 2 years). ${ }^{108}$

\section{Procoagulant Work up}

Once the diagnosis of PVT is made, extensive investigation of prothrombotic disorders and local factors is recommen$\operatorname{ded}^{8,15,109}$ especially for patients with a life expectancy of more than 3-6 months and where anticoagulation is considered relevant. A list of procoagulant work up is given in Table 2. Differential diagnosis for various forms of PVT is given in Table 3.

\section{PROGNOSIS}

\section{Acute Non-cirrhotic Portal Vein Thrombosis}

Mortality in the past was $20 \%-50 \%$ with acute portal vein thrombosis and other splanchnic vessels, but with an early 
Table 2 Procoagulant Work Up.

\begin{tabular}{ll}
\hline Thrombophiliac state & \multicolumn{1}{c}{ Test } \\
\hline Myeloproliferative disorder & V617F JAK2 mutation \\
$\begin{array}{l}\text { Prothrombin/Factor II gene } \\
\text { mutation }\end{array}$ & G20210A mutation \\
\hline Factor V Leiden mutation & $\begin{array}{l}\text { Increased protein C resistance, } \\
\text { R605Q factor V mutation }\end{array}$ \\
\hline Protein C deficiency & $\begin{array}{l}\text { Decreased protein C levels plus } \\
\text { normal PT/positive family history }\end{array}$ \\
\hline Protein S deficiency & $\begin{array}{l}\text { Decreased protein S levels plus } \\
\text { normal PT/positive family history }\end{array}$ \\
\hline Antithrombin deficiency & $\begin{array}{l}\text { Decreased antithrombin levels } \\
\text { plus normal PT/positive family } \\
\text { history }\end{array}$ \\
\hline Antiphospholipid syndrome & $\begin{array}{l}\text { High anti-cardiolipin antibodies/ } \\
\text { lupus anticoagulant/antibeta 2 } \\
\text { glycoprotein 1 antibodies plus } \\
\text { clinical criteria }\end{array}$ \\
\hline PNH (paroxysmal nocturnal & $\begin{array}{l}\text { Flow cytometry for CD 55 ad } \\
\text { CD59 deficient clones }\end{array}$ \\
\hline hemoglobinuria) & Increased homocysteine levels \\
\hline Hyperhomocysteinemia &
\end{tabular}

diagnosis, increased clinical awareness, improved diagnostic techniques and use of early anticoagulation the $5 \mathrm{yr}$ survival rate has improved to $85 \% \cdot{ }^{110,111}$ Outcome of PVT is generally good and mortality primarily is due to underlying cause and less to consequences of portal hypertension. Acute PVT usually has a good prognosis when treated before the occurrence of intestinal infarction. However in the event of bowel infarction and multi organ failure, the in hospital mortality is approximately $20-50 \% .{ }^{112}$ Mortality is highest at one year in patients with cancer or cirrhosis compared with those without ( $26 \%$ vs $8 \%) .{ }^{40}$ Bleeding related mortality in patients with PVT is much lower than in patients with cirrhosis due to preserved liver function.

\section{Chronic Portal Vein Thrombosis}

The overall mortality in chronic onset PVT is less than $10 \%, 113$ whereas in cirrhosis and malignancy, it is $26 \% .{ }^{17}$ A multivariate analysis done on determinants of survival in extra hepatic portal vein thrombosis showed that advanced age, malignancy, cirrhosis, mesenteric vein thrombosis, absence of abdominal inflammation, serum levels of aminotransferase and albumin are associated with reduced survival and not to complications of portal hypertension. ${ }^{15}$ Chronic PVT did not show any extension of the thrombus as shown by repeat imaging after as long as 10 years. ${ }^{114}$ Bleeding after initial variceal eradication occurs usually within first 4-10 years and the risk of bleeding reduces as age progresses especially after 10 years. ${ }^{115}$ Liver dysfunction in long term is a concern and other long term consequences in nutrition, mental function and portal biliopathy.
Table 3 Differential Diagnosis for Variants of PVT.

\begin{tabular}{|c|c|c|}
\hline Variant of PVT & Differentials & Differentiating features \\
\hline Acute PVT & $\begin{array}{l}\text { Acute abdominal } \\
\text { conditions like } \\
\text { pancreatitis, } \\
\text { cholecystitis, } \\
\text { appendicitis, } \\
\text { cholangitis, liver } \\
\text { abscess, abd. surgery } \\
\text { or trauma }\end{array}$ & $\begin{array}{l}\text { US/CT/MRI will detect } \\
\text { fresh thrombus or any local } \\
\text { intra-abdominal } \\
\text { inflammatory focus or both } \\
\text { together }\end{array}$ \\
\hline \multirow[t]{2}{*}{$\begin{array}{l}\text { Chronic PVT } \\
\text { (EHPVO) }\end{array}$} & $\begin{array}{l}\text { NCPF (Non-cirrhotic } \\
\text { portal fibrosis) }\end{array}$ & $\begin{array}{l}\text { Age of presentation varies, } \\
\text { Imaging shows preserved } \\
\text { portal vein in NCPF and } \\
\text { cavernoma formation in } \\
\text { EHPV }\end{array}$ \\
\hline & Cirrhosis & $\begin{array}{l}\text { Ascites, jaundice, hepatic } \\
\text { encephalopathy are } \\
\text { common in cirrhosis and } \\
\text { uncommon in EHPVO. Liver } \\
\text { functions are preserved in } \\
\text { EHPVO. Splenomegaly is } \\
\text { mild in cirrhosis unlike } \\
\text { EHPVO. Imaging shows } \\
\text { irregular liver outline and } \\
\text { dilated portal vein in } \\
\text { cirrhosis. }\end{array}$ \\
\hline \multirow[t]{2}{*}{ PVT in cirrhosis } & PVT (bland thrombosis) & $\begin{array}{l}\text { CT shows non-enhancing } \\
\text { filling defect in the } \\
\text { background of cirrhotic } \\
\text { liver }\end{array}$ \\
\hline & $\begin{array}{l}\text { PV invasion by HCC } \\
\text { (in cirrhosis) }\end{array}$ & $\begin{array}{l}\text { CT shows filling defect with } \\
\text { rim enhancement of vessel } \\
\text { wall (due to malignant } \\
\text { invasion), disruption of } \\
\text { vessel wall, expansile } \\
\text { effect due to tumor mass } \\
\text { and tumor itself also (with } \\
\text { or without underlying } \\
\text { cirrhotic liver) }\end{array}$ \\
\hline
\end{tabular}

\section{Portal Vein Thrombosis in Cirrhosis}

A recent study on natural course of non-malignant partial PVT in cirrhosis showed that untreated partial PVT progressed in $48 \%$, improved in $45 \%$ and was stable in $7 \%$. The probability of hepatic decompensation at 1 and 2 years was $41 \%$ and $57 \%$ respectively. The survival rates at 1 and 2 years were $77 \%$ and $57 \%$ respectively. The progression or regression of partial PVT did not affect the clinical outcome. ${ }^{116}$

\section{TREATMENT}

\section{Anticoagulation}

The aim of the treatment is to reverse or prevent advancement of thrombosis in the portal venous system and to treat complications of established PVT. Most of the management decisions have to be individualized depending on the local expertise, since there is lack of randomized controlled trials. A systematic review reported that upto 
83.3\% of cases of acute PVT do not recanalise in the absence of anticoagulation and the remaining $16.7 \%$ cases that recanalized occurred in the setting of self limiting illness like acute pancreatitis. ${ }^{117}$ There is a clear recommendation for the use of anticoagulation in non-cirrhotic acute PVT with good safety and efficacy data. The data in the setting of cirrhosis is limited and the current guidelines do not give clear directions towards the management of PVT in cirrhosis. However certain situations require a strong recommendation for early use of anticoagulation like, in the setting of intestinal ischemia heralding an infarction, decompensated liver disease awaiting liver transplantation, compensated liver disease, PVT presenting with acute variceal bleed and even asymptomatic patients with mesenteric venous occlusion, whereas unsuitability for liver transplant in advanced liver disease and cavernoma formation in the absence of thrombotic risk factors are situations where anticoagulation may not benefit survival and outcomes.

\section{Non-cirrhotic Acute Portal Vein Thrombosis}

\section{Anticoagulation in Non-cirrhotic Acute Portal Vein Thrombosis}

A recent systematic review of various studies on management of acute non-malignant non-cirrhotic PVT demonstrated the variability in location and extent of the thrombus, methods in initiating anticoagulation whether intravenous, subcutaneous or oral. ${ }^{117}$ The recanalization rates were complete in $38.3 \%$ and partial in $14 \%$, overall $52.3 \%$ (complete plus partial). The time for recanalization varied from 1 to 197 days, which may have been overestimated due to time lag between diagnosis to performance of a repeat imaging. Nonetheless the long duration for recanalization to occur as demonstrated in certain studies could suggest that the anticoagulation duration may actually be indicated for upto 6 months duration. Although few authors recommended lifelong anticoagulation in case of prothrombotic disorder, certain studies gave anticoagulation for lifelong irrespective of the etiology. Follow up of upto 12 months in majority and development of portal cavernoma occurred in $19.9 \%$ patients. Minor complication is reported in 3 cases, retroperitoneal bleed in 1 and gum bleed/epistaxis in 2 patients. Varices were seen in 47 patients and variceal bleed occurred in 5 patients, all five had failed to recanalize the portal vein. ${ }^{117}$

A recent multicenter 2 year follow up study evaluated 102 patients of acute PVT unrelated to cirrhosis and anticoagulation was given in 95 patients. ${ }^{45}$ Following anticoagulation 1 year portal vein recanalization rate was $39 \%$ and no recanalization occurred beyond 6 months after initiation of anticoagulation. Splenic vein and superior mesenteric vein patency was achieved in $80 \%$ and $73 \%$ respectively. Ascites and splenic vein thrombosis are independent factors predicting failure of recanalization. ${ }^{45}$ Table 4 summarizes the clinical studies on anticoagulation in acute non-cirrhotic non-malignant PVT.

Table 4 Clinical Studies on Anticoagulation in Acute Non-cirrhotic Non-malignant PVT.

\begin{tabular}{|c|c|c|c|c|c|}
\hline Reference & No. of patients & Drug and dosage & Duration & Recanalization & Complication \\
\hline $\begin{array}{l}\text { Plessier et al }{ }^{45} \\
\text { (2010) }\end{array}$ & $95 / 102$ & $\begin{array}{l}61 \mathrm{LMWH}, 23 \mathrm{UFH}, \\
11 \mathrm{OA}\end{array}$ & - & $39 \%$ & $\begin{array}{l}\text { Portal cavernoma in } \\
40 \% \\
\text { Glbleed-9, intestinal } \\
\text { infarction-2 }\end{array}$ \\
\hline Tumes et al ${ }^{13}$ (2008) & 27 & $\begin{array}{l}\text { IV OR LMWH, } \\
\text { OA }\end{array}$ & $\begin{array}{l}\text { OA } 6 \text { months or } \\
\text { lifelong in case of } \\
\text { prothrombotic risk }\end{array}$ & $\begin{array}{l}44 \% \text { ( } 22 \% \text { complete } \\
\text { and } 22 \% \text { partial) }\end{array}$ & $\begin{array}{l}1 \text { retroperitoneal } \\
\text { hematoma, variceal } \\
\text { bleed in } 4 \text {, ascites in } \\
5\end{array}$ \\
\hline $\begin{array}{l}\text { Sogaard et } \mathrm{al}^{17} \\
(2007)\end{array}$ & 17 & $\begin{array}{l}\text { Not specified (16/ } \\
\text { 17) anticoagulated }\end{array}$ & - & $\begin{array}{l}10 \text { had improved } \\
\text { flow }\end{array}$ & $\begin{array}{l}47 \% \text { varices, no } \\
\text { bleed, } 47 \% \text { ascites }\end{array}$ \\
\hline $\begin{array}{l}\text { Amitrano et } \text { al }^{114} \\
(2007)\end{array}$ & 21 & $\begin{array}{l}\text { LMWH } 200 \mathrm{IU} / \mathrm{kg} / \mathrm{d} \text {, } \\
\text { OA }\end{array}$ & $\begin{array}{l}\text { OA } 6 \text { months (lifelong } \\
\text { if } \\
\text { bowel resection, } \\
\text { incomplete } \\
\text { recanalization or } \\
\text { thrombophila) }\end{array}$ & $45.5 \%$ complete & $\begin{array}{l}\text { Minor gum bleed/ } \\
\text { epistaxis in 2, } \\
\text { Rethrombosis at } 22 \\
\text { months }\end{array}$ \\
\hline $\begin{array}{l}\text { Romano et al }{ }^{118} \\
(2006)\end{array}$ & 12 & IV heparin, OA & - & $58.3 \%$ & - \\
\hline $\begin{array}{l}\text { Condat B et } \mathrm{al}^{111} \\
(2000)\end{array}$ & $\begin{array}{l}\text { 33-recent PVT, 108- } \\
\text { portal cavernoma }\end{array}$ & IV heparin, OA & 28 days- 4 months & $\begin{array}{l}\text { 10/27-complete } \\
\text { 15/27-partial } \\
\text { 2/27-none }\end{array}$ & $\begin{array}{l}1 \text { had } 2 \text { variceal } \\
\text { bleeds, } 1 \\
\text { hemorrhage into } \\
\text { ovarian cyst }\end{array}$ \\
\hline $\begin{array}{l}\text { Sheen et } \mathrm{al}^{119} \\
(2000)\end{array}$ & 9 & IV heparin, OA & 3 months $\mathrm{OA}$ & $\begin{array}{l}55.5 \% \text {, at median } \\
197 \text { days from } \\
\text { diagnosis }\end{array}$ & - \\
\hline
\end{tabular}


The duration of anticoagulation is not well defined. Recanalization occurs within 4-6 months after anticoagulation, hence these patients should be kept on anticoagulation for at least 6 months. Long term anticoagulation may be recommended in patients with identified prothrombotic disorders, recurrent episodes of thrombosis or family history of venous thrombosis. ${ }^{120}$ Anticoagulation should be initiated with heparin \& maintained for 2-3 week. Later oral Vit $\mathrm{K}$ antagonists should be given to maintain an INR of 2-3. There is more controversy of its role in chronic PVT. There is insufficient evidence for starting anticoagulation in patients with portal cavernoma, although recanalization in partial PVT has been reported in patients with cirrhosis. ${ }^{121}$ Anticoagulation has also been shown to reverse biliary abnormalities due to acute portal vein thrombosis. ${ }^{122}$ Early initiation of anticoagulation preferably within 30 days of symptoms is recommended since no spontaneous recanalization is reported except in acute pancreatitis. Recanalization decreases from $69 \%$ when anticoagulation was instituted within first week to $25 \%$ when instituted at 2 nd week. ${ }^{13}$ Thirty five percent of acute PVT show recanalization with early anticoagulation. ${ }^{13,45,111}$ In another study early anticoagulation could achieve recanalization in 12 of $27(40 \%)$ patients without cirrhosis and malignancy compared with none of the 11 patients who were not given anticoagulation. Varices appeared as early as 1 month after PVT. ${ }^{15}$ In yet another study anticoagulation was able to achieve recanalization of acute splanchnic venous thrombosis in $45.4 \%$ of patients and prevented them from recurrent thrombosis when given lifelong. ${ }^{114}$ Recanalization is less likely, if the thrombosis is extensive due to more than one prothrombotic disorder and associated with ascites. ${ }^{114}$ Early anticoagulation in mesenteric and portal vein thrombosis minimizes serious complications like peritonitis due to bowel necrosis and also significantly decreases the development of esophageal varices related complications. ${ }^{13,121}$

The outcome of portal vein thrombosis in adults has been studied in relation to anticoagulation. Out of $136 \mathrm{pa}-$ tients of non-cirrhotic non-malignant portal vein thrombosis, 84 received anticoagulation. Over a median follow up of 46 months, the incidence rate of gastrointestinal bleeding was 12.5 (95\% confidence interval [CI], 10-15) per 100 patient-years. Large varices were an independent predictor for bleeding. Anticoagulant therapy did not increase the risk or the severity of bleeding. The incidence rate of thrombotic events was 5.5 (95\% CI, 3.8-7.2) per 100 patient-years. Underlying prothrombotic state and absence of anticoagulant therapy were independent predictors for thrombosis. In patients with underlying prothrombotic state, the incidence rates of splanchnic venous infarction were 0.82 and 5.2 per 100 patient-years in periods with and without anticoagulant therapy, respectively $(P=0.01)$. Two non-anticoagulated patients died of bleeding and thrombosis, respectively. ${ }^{40}$ Another recent retrospective data of 120 patients of non-cirrhotic portal vein thrombosis showed that of 66 patients who were anticoagulated, the overall thrombotic risk at 1, 5, 10 years was $4 \%, 8 \%$ and $27 \%$ respectively. The presence of a prothrombotic disorder was the only independent predictor of recurrent thrombosis and use of anticoagulation tended to reduce the risk. Eighty three gastrointestinal bleed events occurred in 37 patients and the rebleeding risk at 1, 5, 10 years was $19 \%, 46 \%$ and $49 \%$ respectively. Anticoagulation therapy was a predictor of bleed but not associated with severity of the bleeding. ${ }^{123}$

\section{Thrombolysis in Non-cirrbotic Acute Portal Vein Thrombosis}

Thrombolytic therapy in very recent portal vein thrombosis can be done via indirect intraarterial infusion into the superior mesenteric artery or directly via catheter introduced into portal vein either transhepatically or through transjugular approach and may improve regional clot lysis. ${ }^{124-127}$ Catheterization of SMA operatively and intraarterial infusion of thrombolytic drugs like recombinant tissue plasminogen activator, ${ }^{128}$ urokinase and streptokinase have all been shown to have gratifying results. ${ }^{129}$ Indirect infusion of thrombolytics into SMA is technically less demanding but does not allow direct infusion into the thrombus. As a result the thrombolytics have a propensity to be diverted into the collaterals and prolong the total infusion into SMA. Prolonged catheterization may itself pose a risk of embolizing SMA and its arterial branches itself. Direct access to portal vein via transjugular or percutaneous intrahepatic route targets the thrombus directly and improvement in flow and clinical symptoms. It also has the advantage of being less time consuming, more efficient and reduced dose of thrombolytics thereby reducing the thrombolysis related complications. Liu FY et $\mathrm{al}^{130}$ described a case series of 46 patients of acute symptomatic portal-meseteric venous thrombosis treated with thrombolysis. They were treated with interventional therapy, including direct thrombolysis (26 cases through a transjugular intrahepatic portosystemic shunt; 6 through percutaneous transhepatic portal vein cannulation) and indirect thrombolysis (10 through the femoral artery to superior mesenteric artery catheterization; 4 through the radial artery to superior mesenteric artery catheterization). Complete or partial success was achieved in 34 patients. In 11 patients with no reperfusion collateral vessels increased significantly. Symptoms improved dramatically in these 45 patients however 1 patient who did not respond had bowel necrosis requiring surgical intervention. ${ }^{130}$ A retrospective review of 33 cases of portal vein thrombosis treated with conservative treatment in 5 , all of whom died and with thrombolysis using streptokinase or rtPA in 28 patients. Recanalization was noted in 10 patients, all of whom had history of less than 2 weeks. In patients with longer duration of history, partial occlusion persisted in 13 patients. In 
5 patients with history of more than $30-40$ days, thrombolysis failed. Four patients died ( 2 from portal rethrombosis, 1 each due to liver failure and cerebral stroke). ${ }^{66}$ In a series of 20 patients with acute or subacute portal and mesenteric vein thrombosis with severe symptoms treatment with thrombolytic therapy was initiated via transhepatic, common femoral or SMA routes. Fifteen of the 20 patients exhibited some degree of lysis of the thrombosis, 3 having complete resolution, 12 partial and five no resolution. Eighty five percent had resolution of symptoms, but major complications including bleeding developed in $60 \% \mathrm{pa}-$ tients. The investigators felt thus that thrombolytic therapy should be reserved for patients with severe disease. Most centers now tend to choose a more conservative therapeutic strategy. ${ }^{127}$ Another series of 12 patients with acute symptomatic superior mesenteric vein thrombosis treated with urokinase infusion via transjugular route resulted in substantial clinical improvement and technical success in all. SMV thrombosis disappeared in all with no recurrence of thrombotic episode. However all these patients had failed anticoagulation therapy and subsequently intervened by thrombolysis. ${ }^{131}$ Another 12 patient series of thrombolysis showed complete success in three and partial in four patients. Minor bleeding was noted in two (17\%) and major bleeding in six $(50 \%)$ with a fatal outcome in two. ${ }^{132}$ Thrombolysis via omental vein catheterization and via creation of intrahepatic portosystemic shunts (IPS) have also been reported. ${ }^{1}$

\section{Thrombectomy}

Surgical thrombectomy is associated with recurrence of thrombosis, surgical morbidity and mortality and hence not recommended. Mechanical thrombectomy by percutaneous transhepatic route has the advantage of rapidly removing thrombus in a recently developed PVT $(<30$ days) although its drawbacks include intimal or vascular trauma to the portal vein, that may promote recurrent thrombosis. ${ }^{135}$ Percutaneous transhepatic thromboaspiration within $72 \mathrm{~h}$ has been done successfully in some patients. ${ }^{136}$ Mechanical aspiration thromobectomy during TIPs placement has also been attempted successfully. ${ }^{137}$ Pharmacological lysis of the thrombus with local urokinase and local removal of the clot allowed restoration of normal blood flow to the liver in three patients who developed PVT following liver transplantation. Balloon dilation and placement of vascular stent are helpful in decreasing the risk of recurrent thrombosis where a defective surgical technique is the reason for thrombosis. ${ }^{138}$

\section{Portal Vein Thrombosis in Cirrhosis}

\section{Anticoagulation in Cirrhotic Portal Vein Thrombosis}

In patients with cirrhosis there are only few studies on the use of anticoagulation for PVT. The numbers have been small in these studies and majority was partial PVT. The treatment regimens mainly used low molecular weight heparin (LMWH), one study also used oral Vitamin K antagonist. Complete recanalization rates achieved with anticoagulation are $42-75 \%$ and the risk of extension of thrombosis is $5-7 \%$ only. The choice of anticoagulant is not clearly certain. However the studies on cirrhosis have predominantly used low molecular weight heparin than unfractionated heparin (UFH) in the treatment of PVT with an advantage of no monitoring requirement, lower bleeding risk and risk of thrombocytopenia with LMWH. LMWH when compared to oral anticoagulants where INR monitoring is a complicated issue as a whole in the setting of cirrhosis again has an advantage. The control of bleeding related to oral anticoagulant use is also difficult to predict due to prolonged half life and anticoagulant effects of oral drugs. Studies on the use of anticoagulation in cirrhosis with portal vein thrombosis are limited and are shown in Table 5.

Newer oral anticoagulants in portal vein thrombosis have not been studied. However a recent case report of the use of rivaroxaban (orally active direct factor Xa inhibitor) in Child A NASH related cirrhosis with acute PVT and MVT was reported. Unfractionated heparin followed by transition to oral rivaroxaban $20 \mathrm{mg}$ daily was given for 6 months. There was complete dissolution of the clot on repeat imaging at 6 months. ${ }^{145}$ Due to its predominant hepatic metabolism it is currently contra indicated in Child B and $\mathrm{C}$ cirrhosis, coagulopathy and clinically relevant bleeding risk. Another case of successful treatment of portal vein thrombosis has also been reported with rivaroxaban. ${ }^{146}$

\section{Thrombolysis in Cirrbotic Portal Vein Thrombosis}

A pilot study of systemic thrombolysis in 9 patients of cirrhosis with portal vein thrombosis was performed with rtPA a plus low molecular weight heparin. Complete regression of thrombosis was achieved in 4, partial in 4 and none in 1 . There were no significant side effects. ${ }^{147}$

\section{Role as Prophylactic Anticoagulation to Prevent Portal Vein Thrombosis}

Low molecular weight heparin has been shown to prevent portal vein thrombosis and liver decompensation in patients with advanced cirrhosis in a recent randomized controlled trial. ${ }^{148}$ The trial showed that enoxaparin (4000 IU/day, subcutaneously for 48 weeks) was effective in preventing PVT in cirrhosis with Child score 7-10 such that no patient in enoxaparin group developed PVT compared to placebo group (16.6\%). Liver decompensation was less in enoxaparin group (11.7\%) than controls (59.4\%) and actuarial probability of survival was higher. ${ }^{148}$ Enoxaparin was safe with no significant side effects or hemorrhagic events. It is too early to recommend anticoagulation for a prophylactic role in preventing PVT due to limited data availability. 
Table 5 Studies on the Use of Anticoagulation in Cirrhosis with PVT.

\begin{tabular}{|c|c|c|c|c|c|}
\hline Reference & No. of patients & Drug and dosage & Duration & Recanalization & Complication \\
\hline $\begin{array}{l}\text { Amitrano et } \text { al }^{139} \\
(2010)\end{array}$ & 28 uncontrolled & $\begin{array}{l}\text { Enoxaparin } 200 \mathrm{u} / \\
\mathrm{kg} / \mathrm{d}\end{array}$ & 6 months & $\begin{array}{l}\text { Complete-21 } \\
\text { Partial-2 }\end{array}$ & None \\
\hline $\begin{array}{l}\text { Francoz et al }{ }^{121} \\
(2005)\end{array}$ & 19 cohort study & $\begin{array}{l}\text { LMWH (Nadroparin) } \\
5700 \mathrm{IU} / \mathrm{d} \text {, followed } \\
\text { by VKA }\end{array}$ & & Complete-8 & $\begin{array}{l}\text { Post EVL ulcer bleed- } \\
1\end{array}$ \\
\hline $\begin{array}{l}\text { Senzolo et al }{ }^{140} \\
(2009)\end{array}$ & 33 uncontrolled & $\begin{array}{l}\text { LMWH antiXa } 95 \mathrm{U} / \\
\mathrm{kg} / \mathrm{bw} \text { TID }\end{array}$ & & $\begin{array}{l}\text { Complete-12 } \\
\text { Partial-9 }\end{array}$ & $\begin{array}{l}\text { HIT-1, Non-variceal } \\
\text { bleed-1 }\end{array}$ \\
\hline $\begin{array}{l}\text { Pellicelli et } \mathrm{al}^{141} \\
(2010)\end{array}$ & 9 uncontrolled & $\begin{array}{l}\text { Enoxaparin } 100 \mathrm{U} / \\
\mathrm{kg} / \mathrm{d}\end{array}$ & 3-4months & $\begin{array}{l}\text { Complete-3 } \\
\text { Partial-6 }\end{array}$ & None \\
\hline $\begin{array}{l}\text { Warmer et al }{ }^{142} \\
(2012)\end{array}$ & 28 uncontrolled & Warfarin & $\begin{array}{l}1 \text { year or until } \\
\text { recanalization }\end{array}$ & $\begin{array}{l}\text { Complete-11 } \\
\text { Partial-12 }\end{array}$ & Vaginal bleed-1 \\
\hline $\begin{array}{l}\text { Delgado et } \text { al }^{143} \\
(2012)\end{array}$ & 55 uncontrolled & $\begin{array}{l}\text { LMWH (in } 27,21 \\
\text { shifted to VKA), VKA } \\
\text { (in 8) }\end{array}$ & & $\begin{array}{l}\text { Complete-25 } \\
\text { Partial-8 }\end{array}$ & $\begin{array}{l}\text { Non-variceal bleed- } 5 \\
\text { Variceal bleed-6 }\end{array}$ \\
\hline $\begin{array}{l}\text { Senzolo et } \mathrm{al}^{144} \\
(2012)\end{array}$ & $\begin{array}{l}56 \text { non-randomized, } \\
\text { Treatment group-35 } \\
\text { Control-21 }\end{array}$ & $\begin{array}{l}\text { Nadroparin (95 } \\
\text { antiXa U/kg body } \\
\text { weight) TID ( } n=33) \text {, } \\
2 \text { had portal } \\
\text { cavernoma }\end{array}$ & & $\begin{array}{l}\text { Treatment group: } \\
\text { Complete-12 } \\
\text { Partial-9 } \\
\text { Control: } \\
\text { Complete-1 } \\
\text { Thrombus } \\
\text { progression in } \\
\text { treatment group was } \\
5 \text { and control was } 15 \\
(P<0.001) \text {, TIPS } \\
\text { placed in } 6 \text { patients }\end{array}$ & $\begin{array}{l}\text { Treatment group: } \\
\text { Variceal bleed-1 } \\
\text { Control: } \\
\text { Variceal bleed-5, } \\
\text { intestinal ischemia-2 }\end{array}$ \\
\hline
\end{tabular}

\section{CHRONIC PORTAL VEIN THROMBOSIS (EXTRA HEPATIC PORTAL VENOUS OBSTRUCTION)}

\section{Endotherapy}

Acute gastrointestinal bleeding due to varices is treated in a similar way as in cirrhotics with endotherapy. There is no study on the use of vasopressors, although there may be a slightly increased risk of PVT in view of presence of procoagulant factors. No studies have addressed the role of primary prophylaxis in PVT associated portal hypertension. There is concern of extension of thrombosis with beta-blockers as well as vasopressors due to decrease in splanchnic blood flow. ${ }^{108}$ No report has addressed this complication with terlipressin; but a case report does exist with use of vasopressin. ${ }^{149}$

Two retrospective studies have suggested that beta adrenergic blockade may play a role in secondary prophylaxis as they reduce the risk of rebleeding and improve survival after variceal bleed. ${ }^{40}$ Endoscopic variceal ligation is safe and highly effective in children and adults with PVT. ${ }^{150,151}$ Band ligation plus sclerotherapy is considered to be better in treating children with chronic PVT than EST alone as it required fewer sessions and fewer complications. ${ }^{152}$ Our study has shown that variceal obliteration following endoscopic sclerotherapy opens up spontaneous shunts due to a possible increase in portal pressure in $40 \%$ of patients, which in turn protects these patients from further bleeds and recurrence of varices. ${ }^{153}$

Patients with chronic portosystemic venous thrombosis have an acceptable long term outcome with 1 and 5 year survival rates of $85.7 \%$ and $82.1 \%$ respectively. Factors associated with improved survival were use of beta blockers and anticoagulation. Presence of ascites and hyperbilirubinemia at presentation were associated with reduced survival. $^{154}$

\section{Shunt Surgery}

Decompressive shunt surgery should be considered in cases with failed endotherapy although it needs to be borne in mind that $37 \%$ of patients with PVT also have thrombosis of splenic and superior mesenteric vein. ${ }^{155}$ It is also indicated for correcting symptomatic portal hypertensive biliopathy, symptomatic hypersplenism, ectopic variceal bleed, non-compliance to endotherapy, severe growth retardation, poor chances of follow up and "on demand" one time treatment. Shunts may be selective or non-selective. Non-selective shunts are end to side or side to side portocaval, proximal lienorenal, end to side mesocaval and large diameter interposition portocaval or mesocaval shunts. Selective shunts include distal lienorenal shunt, and mesenteric-left portal vein bypass (Rex shunt) which restores mesenteric blood flow to the liver through the 
Rex venous recessus (interposition of a jugular venous allograft between the superior mesenteric vein and the intrahepatic left portal vein), which may improve the growth potential. Warren Zeppa distal splenorenal shunts have been shown to be effective in control of bleeding and long term survival in patients with PVT. ${ }^{156}$ Mesocaval shunts may be necessary when Warren shunt is precluded. Our own study of side to side lienorenal shunts demonstrated that it not only prevented rebleed but also corrected the hypersplenism. ${ }^{157}$

Rex shunt (mesenteric left portal by pass) between the superior mesenteric vein and left portal vein is widely used now and has been considered to be more physiological over other shunts, which do not return blood directly to the liver. ${ }^{158}$ Although commonly done in children its use in adults needs to be validated. ${ }^{159}$ The intrahepatic portal vein is assessed by dissecting the terminal branches of the left portal vein in the recessus of Rex between segments III and IV of the left lobe of the liver. The vein should be relatively large for adequate flow of blood. It should be avoided if cirrhosis coexists. This bypass requires an autologous vein graft. The internal jugular vein provides a suitable and easily obtainable venous conduit. An autogenous saphenous vein, and a cryopreserved graft have also been used at some centers. ${ }^{160}$ A novel shunt approach when other surgical options fail include using the right or left gonadal vein for shunting with mesenteric veins. ${ }^{161}$

\section{Non-shunt Surgery}

Esophageal transection with or without splenectomy is less useful to control bleeding due to a high risk of late rebleeding and reappearance of varices and but can be resorted to as a non-shunt option in patients with portosystemic encephalopathy, hepatopulmonary syndrome or portopulmonary syndrome. ${ }^{162}$ Moreover splenectomy destroys the opportunity to use the splenic vein later for a shunt. In MPD spleen becomes an organ for extramedullary marrow formation and should be preserved. ${ }^{157}$

\section{Anticoagulation in Chronic Portal Vein Thrombosis}

Anticoagulation in chronic PVT has a controversial role. The recommendations for anticoagulation in this setting remain for those with underlying prothrombotic state. The usage of anticoagulation in chronic PVT has been around $30 \%$ in most studies. Condat et $\mathrm{al}^{111}$ had given some information on its use in the setting of chronic PVT with no significant bleeding differences from those without anticoagulation. However there was a significant reduction in new thrombotic episodes. A recent retrospective study by Hoekstra et al showed that the use of anticoagulation in pregnancy with chronic PVT had favorable maternal and fetal outcomes for most pregnancies reaching 20 week gestation, however the rate of miscarriage and preterm delivery appeared to be increased when antico- agulated on individual basis. ${ }^{163}$ Thrombocytosis was a risk factor for unfavorable pregnancy outcome. Variceal bleed occurred in three, all without appropriate primary prophylaxis. No lower limb or mesenteric vein thrombosis occurred during pregnancy or post partum period. ${ }^{163}$ The study also concluded that recommendations still remain the same even in pregnancy as for other patients.

\section{TIPS}

There is a concern for the use of TIPS in the setting of portal vein thrombosis due to the technical reasons of performing TIPS, inability to use in advanced cirrhosis and may hamper transplant later in case of a misplacement. However the use of TIPS in PVT has been studied with possibility of achieving recanalization by disrupting the thrombus and mechanical thrombectomy. The feasibility rate of performing TIPS in PVT ranges between 75 and 100\%. Hepatic encephalopathy may be seen in $4-27 \%$ and TIPS dysfunction in $20-38 \%$ of patients. ${ }^{164}$ Long term anticoagulation use varies from 11 to $100 \%$ due to study designs. ${ }^{164}$ Studies have shown long term patency rates even without anticoagulation in TIPS, hence routine anticoagulant use may not be recommended after TIPS placement except in those patients with prothrombotic states. In a few cases with PVT, TIPS has been shown to be successful ${ }^{165,166}$ in treating patients with portal biliopathy and portal vein thrombosis complicating Budd-Chiari syndrome. In 23 of the 28 patients with complete portal vein thrombosis success was achieved in 73\% including 6 of 9 patients with cavernomatous transformation. ${ }^{165}$ Another study on TIPS performed on 15 patients with cirrhosis and PVT leading to refractory ascites, variceal hemorrhage and refractory pleural effusion showed its success in $75 \%(3 / 4)$ patients with cavernomatous transformation and 10/11 (94\%) patients with acute PVT with an overall survival of $87 \%$. It may thus be a treatment option in certain patients. ${ }^{167}$ In chronic PVT (portal cavernoma) TIPS placement has been successful in $35 \%-80 \%{ }^{168-171}$ TIPS is unsuccessful if the lumen of thrombosed portal vein is not catheterizable and cavernomatous vein is not amenable to dilatation.

\section{LIVER TRANSPLANT (LT) IN PORTAL VEIN THROMBOSIS}

PVT was considered to be a major obstacle to liver transplantation which led to increased surgical complexity and perioperative morbidity and mortality. Following the successful LT in the presence of PVT in 1985, experience has increased in this condition. ${ }^{172}$ Portal vein thrombosis is associated with greater operative complexity and rethrombosis but has no influence on overall morbidity and mortality. ${ }^{173}$ Liver transplantation in PVT however has been associated with an increased operative time, transfusion requirements, reintervention and lower survival rate 
depending on PVT extension. ${ }^{174}$ Surgical techniques like thrombectomy, thromboendovenectomy with venous reconstitution, interposition of vein graft, portocaval liver transposition have all been done including radiological endovascular interventions to overcome venous obstruction in the recipient. ${ }^{175}$

The most frequent technique employed is thrombectomy/thromboendovenectomy with end to end donorrecipient portal anastomosis $(75 \%) .{ }^{176}$ Other techniques that follow are venous jump graft interposition between donor and recipient PV (8.4\%), low dissection of PV (5\%), portocaval hemitransposition (end to side or end to end, $3.3 \%)$, collateral vessel as influx (2.4\%), extra anatomic reconstruction involving autologous vessels (1.4\%), and arterialization of PV $(0.2 \%)$. Various classification systems exist for PVT grading in cirrhosis. ${ }^{176}$ As per Yerdel's grading, for the purpose of liver transplantation PVT has been classified into four grades i.e. Grade 1 PV minimal or partially thrombosed less than $50 \%$ of the vessel lumen, Grade 2 more than $50 \%$ occlusion of the PV including total occlusion, Grade 3 complete thrombosis of both PV and proximal SMV, Grade 4 complete thrombosis of PV as well as proximal and distal SMV. ${ }^{177}$ While patients with Grade 1-2 PVT can be adequately managed by terminal to terminal portal vein anastomosis with or without thrombectomy with an advantage that it maintains the portal physiology. Those with Grade 3 PVT in the absence of available distal SMV segments for PV reconstruction, dilated branches of recipient portal venous system could be selected as inflow vessels or anastomosis to the coronary vein can be performed. In the absence of a suitable vein, interposition graft of donor iliac vein may be anastomosed to the SMV. With Grade 4 PVT classic porto-caval hemitransposition is a widely accepted approach, however renoportal anastomosis or anastomosis to the coronary vein or large collateral vessel is also an option. Residual portal hypertension is seen in approximately $50 \%$ with the use of portocaval hemitransposition or renoportal anastomosis. ${ }^{176}$ Overall variceal bleeding risk is $20 \%$, persistent ascites in $58 \%$ and renal dysfunction in $26 \%$. In patients with diffuse portal mesenteric vein thrombosis, combined liver intestine transplantation has been advocated. ${ }^{176}$

Rethrombosis has been reported in $10.3 \%$ in the absence of a preventive strategy and it decreases to $6.1 \%$ with the utilization of anticoagulation for prevention of rethrombosis in a systematic review. Male sex, prior PVT therapy, Child C class and alcoholic liver disease are the risk factors for recurrence. Intra portal pump use temporarily has also been shown to have reduced rethrombosis rates (7\% vs $30 \%) .{ }^{176}$

Forty two of the 465 liver transplants have been done at a center with associated PVT. This study found a higher incidence of rethrombosis ( $7.1 \%$ vs $0.9 \%$ ) and renal failure ( $16.7 \%$ vs $8.5 \%$ ) because of complex surgical procedure damaging the portal vein thrombosis and prolonged an hepatic phase. ${ }^{177}$ Liver transplant is indicated in a rare pa- tient to life threatening complications of PVT not manageable conservatively or by shunt surgery as in those with encephalopathy, hypoxia or pulmonary artery hypertension. Outcome in patients with PVT is dependent on the preoperative liver disease severity as patients with a MELD of $<15$ and PVT had a decreased 1 y survival as compared with those without PVT (57\% vs $89 \%$ ) while those with a MELD > 15 and PVT had an equal and slightly better survival vs non-PVT patients ( 1 y survival $91 \%$ vs $75 \%$ ) with an only slightly increased morbidity. ${ }^{178}$ Liver transplant has also been reported in a patient with bile duct complications due to cavernoma. ${ }^{179}$

\section{PORTAL VEIN THROMBOSIS IN SPECIAL SITUATIONS}

\section{Portal Cholangiopathy}

Portal cholangiopathy has been dealt with in detail in a separate issue in the same journal Vol 4 March 2014Ss1S98-supplement 2.

\section{Portal Vein Obstruction in HCC}

HCC is commonly associated with portal vein obstruction. It is associated with worse survival and indicates advanced disease. Advanced stage, higher CTP class, major vessel involvement, low serum albumin and high AFP levels are predictive of PV obstruction in patients with HCC. ${ }^{180}$ In a study on thrombophilic genetic factors in 94 patients with HCC with \& without PV obstruction, the Odds Ratio was 3.85 for MTHFR C6777TT with HCC versus healthy controls. Prothrombin gene G20210A mutation was also more frequent among HCC patients mainly with PV obstruction thereby concluding that all cirrhotics should be looked for thrombophilic genetic factors to individualize patients at risk for PV obstruction in HCC. ${ }^{181}$ Survival in PV obstruction and HCC has been shown to be better in those with normal AFP. ${ }^{182}$

Contrast enhanced US (CEUS) has been found to be superior than color Doppler sonography, conventional US, and $\mathrm{CT}$ in PV invasion detection and characterization complicating hepatic malignancies. ${ }^{183}$ In a study CEUS detected tumor invasion in $100 \%$ and correctly characterized it in $98 \%$ of patients, while CT detected tumor invasion in $68 \%$ and correctly characterized it in $68 \%$ of them, CEUS may thus be helpful in staging HCC. ${ }^{184}$

Patients with small HCC and PV obstruction can be safely treated with RFA. ${ }^{185}$ Similarly Yttrium -90 glass microspheres (Theraspheres) appear to be safe and well tolerated in patients with portal vein obstruction without cavernous transformation. ${ }^{186}$ Similarly conformal radiotherapy induced a $45.8 \%$ objective response rate for $\mathrm{PV}$ obstruction in HCC and may be considered an important treatment option. ${ }^{187}$ Patients with PV obstruction in the setting of HCC has a poor patient outcome. Patients should 
be assessed preoperatively whether the thrombus is associated with tumor invasion or with stagnant flow. In a study of 12 consecutive patients who underwent liver transplantation for HCC in the setting of PV obstruction $42 \%$ had no evident portal vein invasion and only $17 \%$ had tumor invasion. Only one third experienced tumor recurrence in first year post transplant and one third became long term survivors (median 36 months) with no evidence of tumor recurrence. ${ }^{187}$ Radiation therapy is considered to be treatment of choice for selected patients with HCC and PV invasion especially for those with a favorable performance status. ${ }^{188} \mathrm{~A}$ recent phase 2 study of Yttrium 90 radioembolization (TARE-trans arterial radioembolization) in intermediate and advanced HCC showed a median survival of 15 months with no significant difference between PV obstruction present or absent. ${ }^{189}$ However the responders had a significantly higher median survival than non-responders. The median time to progression was 11 months with TARE. ${ }^{190}$

\section{CONCLUSION}

Portal vein thrombosis is being increasingly recognized in non-cirrhotic, cirrhosis and in malignant conditions like hepatocellular carcinoma. The identification of an underlying hypercoagulable state is possible in more than $80 \%$ of cases with rigorous search. The presentation is variable in acute and chronic PVT and imaging helps in differentiating the two different presentations. Doppler ultrasound detects most of the cases adequately however advanced imaging with CT or MRI may be required for defining the extent of thrombosis and planning a shunt surgery. In non-cirrhotic non-malignant acute PVT, anticoagulation remains the mainstay of therapy whereas decompressive shunt surgery like Rex shunt should be offered for cavernomatous (chronic) PVT. The data on anticoagulation use in cirrhosis with acute PVT is convincing with appreciable results and no added bleeding risk, and should be offered to patients especially awaiting liver transplantation. However, lack of consensus on the type of anticoagulant to be used, duration of anticoagulation, monitoring of anticoagulation keeps the research on portal vein thrombosis open for debate and opportunity to work on. TIPS is another option for PVT. Liver transplantation in the expert hands is not affected by the portal vein thrombosis or its extent. The prophylactic role of anticoagulants in preventing PVT needs to be studied.

\section{CONFLICTS OF INTEREST}

All authors have none to declare.

\section{REFERENCES}

1. Balfour GW, Stewart TG. Cases of enlarged spleen complicated with ascites, both depending upon varicose dilatation and thrombosis of the portal vein. Edinb Med J. 1869;14:589-598.
2. Okuda K, Ohnishi K, Kimura K, et al. Incidence of portal vein thrombosis in liver cirrhosis. An angiographic study in 708 patients. Gastroenterology. 1985;89:279-286.

3. Gaiani S, Bolondi L, Li BS, Zironi G, Siringo S, Barbara L. Prevalence of spontaneous hepatofugal portal flow in liver cirrhosis. Clinical and endoscopic correlation in 228 patients. Gastroenterology. 1991;100:160-167.

4. Manzanet G, Sanjuan F, Orbis P, et al. Liver transplantation in patients with portal vein thrombosis. Liver Transpl. 2001;7:125131.

5. Amitrano L, Guardascione MA, Brancaccio V, et al. Risk factors and clinical presentation of portal vein thrombosis in patients with liver cirrhosis. J Hepatol. 2004;40:736-741.

6. Belli L, Romani F, Sansalone CV, Aseni P, Rondinara G. Portal thrombosis in cirrhotics. A retrospective analysis. Ann Surg. 1986;203:286-291.

7. Ogren M, Bergqvist D, Björck M, Acosta S, Eriksson H, Sternby NH. Portal vein thrombosis: prevalence, patient characteristics and lifetime risk: a population study based on 23,796 consecutive autopsies. World J Gastroenterol. 2006;12:2115-2119.

8. Denninger MH, Chaö̈t Y, Casadevall N, et al. Cause of portal or hepatic venous thrombosis in adults: the role of multiple concurrent factors. Hepatology. 2000;31:587-591.

9. Janssen HL, Meinardi JR, Vleggaar FP, et al. Factor V Leiden mutation, prothrombin gene mutation, and deficiencies in coagulation inhibitors associated with Budd-Chiari syndrome and portal vein thrombosis: results of a case-control study. Blood. 2000;96:2364-2368.

10. Bombeli T, Basic A, Fehr J. Prevalence of hereditary thrombophilia in patients with thrombosis in different venous systems. Am J Hematol. 2002;70:126-132.

11. Bhattacharyya M, Makharia G, Kannan M, Ahmed RPH, Gupta PK, Saxena R. Inherited prothrombotic defects in Budd-Chiari syndrome and portal vein thrombosis - a study from north India. Am J Clin Pathol. 2004;121:844-847.

12. Primignani M, Martinelli I, Bucciarelli $P$, et al. Risk factors for thrombophilia in extrahepatic portal vein obstruction. Hepatology. 2005;41:603-608.

13. Turnes J, García-Pagán JC, González M, et al. Portal hypertensionrelated complications after acute portal vein thrombosis: impact of early anticoagulation. Clin Gastroenterol Hepatol. 2008;6:1412-1417.

14. Rosendaal FR. Venous thrombosis: a multicausal disease. Lancet. 1999;353:1167-1173.

15. Janssen HL, Wijnhoud A, Haagsma EB, et al. Extrahepatic portal vein thrombosis: aetiology and determinants of survival. Gut. 2001;49:720-724.

16. De Franchis R. Evolving consensus in portal hypertension. Report of the Baveno IV consensus workshop on methodology of diagnosis and therapy in portal hypertension. J Hepatol. 2005;43:167-176.

17. Sogaard KK, Astrup LB, Vilstrup H, Gronbaek H. Portal vein thrombosis; risk factors, clinical presentation and treatment. BMC Gastroenterol. 2007;7:34.

18. Condat B, Valla D. Nonmalignant portal vein thrombosis in adults. Nat Clin Prac Gastroenterol Hepatol. 2006;3:505-515.

19. Kiladjian JJ, Cervantes F, Leebeek FW, et al. The impact of JAK2 and MPL mutations on diagnosis and prognosis of splanchnic vein thrombosis: a report on 241 cases. Blood. 2008;111:4922-4929.

20. Patel RK, Lea NC, Heneghan MA, et al. Prevalence of the activating JAK2 tyrosine kinase mutation V617F in the Budd-Chiari syndrome. Gastroenterology. 2006;130:2031-2038.

21. Tefferi A, Thiele J, Orazi A, et al. Proposals and rationale for revision of the World Health Organization diagnostic criteria for 
polycythemia vera, essential thrombocythemia, and primary myelofibrosis: recommendations from an ad hoc international expert panel. Blood. 2007;110:1092-1097.

22. Valla D, Casadevall N, Huisse MG, et al. Myeloproliferative disorders in portal vein thrombosis in adults. Gastroenterology. 1998;94:1063-1069.

23. Hoekstra J, Bresser EL, Smalberg JH, Spaander MC, Leebeek FW, Janssen HL. Long-term follow-up of patients with portal vein thrombosis and myeloproliferative neoplasms. J Thromb Haemost. 2011;9:2208-2214.

24. Smalberg JH, Arends LR, Valla DC, Kiladjian JJ, Janssen HLA, Leebeek FWG. Myeloproliferative neoplasms in Budd-Chiari syndrome and portal vein thrombosis: a meta-analysis. Blood. 2012;120:4021-4028.

25. Qi X, Zhang C, Han G, et al. Prevalence of the JAK2V617F mutation in Chinese patients with Budd-Chiari syndrome and portal vein thrombosis: a prospective study. J Gastroenterol Hepatol. 2012;27:1036-1043.

26. Qi X, Yang Z, Bai M, Shi X, Han G, Fan D. Meta-analysis: the significance of screening for JAK2V617F mutation in Budd-Chiari syndrome and portal venous system thrombosis. Aliment Pharmacol Ther. 2011;33:1087-1103.

27. Deepak A, Punamiya S, Patel N, Parekh S, Mehta S, Shah N. Prevalence of JAK29V617F) mutation in intra-abdominal venous thrombosis. Trop Gastroenterol. 2011;32:279-284.

28. Fisher NC, Wilde JT, Roper J, Elias E. Deficiency of natural anticoagulant proteins $\mathrm{C}, \mathrm{S}$, and antithrombin in portal vein thrombosis: a secondary phenomenon? Gut. 2000;46:534-539.

29. De Bruijne EL, Murad SD, de Maat MP, et al, Liver and Thrombosis Study Group. Genetic variation in thrombin-activatable fibrinolysis inhibitor (TAFI) is associated with the risk of splanchnic vein thrombosis. Thromb Haemost. 2007;97:181-185.

30. Martinelli I, Primignani M, Aghemo A, et al. High levels of factor VIII and risk of extra-hepatic portal vein obstruction. I Hepatol. 2009;50:916-922.

31. D'Amico M, Sammarco P, Pasta L. Thrombophilic genetic factors PAI-1, MTHFRC677T, V Leiden 506Q, and prothrombin 20210A in noncirrhotic portal vein thrombosis and Budd-Chiari syndrome in a caucasian population. Int J Vas Med. 2013;2013:717480. http://dx.doi.org/10.1155/2013/717480. Epub 2013 Dec 18.

32. Qi X, De Stefano V, Wang J, et al. Prevalence of inherited antithrombin, protein $\mathrm{C}$, and protein $\mathrm{S}$ deficiencies in portal vein system thrombosis and Budd-Chiari syndrome: a systematic review and meta-analysis of observational studies. J Gastroenterol Hepatol. 2013;28:432-442.

33. Mohanty D, Shetty S, Ghosh K, Pawar A, Abraham P. Hereditary thrombophilia as a cause of Budd-Chiari syndrome: a study from Western India. Hepatology. 2001;34:666-670.

34. Sharma S, Kumar SI, Poddar U, Yachha SK, Aggarwal R, Factor V. Leiden and prothrombin gene G20210A mutations are uncommon in portal vein thrombosis in India. Indian J Gastroenterol. 2006;25:236-239.

35. Koshy A, Jeyakumari M, Factor V. Leiden is not commonly associated with idiopathic portal vein thrombosis in southern India. Indian J Gastroenterol. 2006;25:140-142.

36. Shah SR, Dasgupta A, Sharma A, Joshi A, Desai D, Abraham P. Thrombophilic conditions in non cirrhotic portal vein thrombosis. Indian J Gastroenterol. 2005;24:205-210.

37. Koshy A, Jeyakumari M. High FVIII level is associated with idiopathic portal vein thrombosis in South India. Am J Med. 2007:120, 552.e9-11.

38. Liappis AP, Roberts AD, Schwartz AM, Simon GL. Thrombosis and infection: a case of transient anti-cardiolipin antibody associated with pylephlebitis. Am J Med Sci. 2003;325:365368.
39. Amitrano L, Guardascione MA, Scaglione M, Menchise A Romano L, Balzano A. Acute portal and mesenteric thrombosis: unusual presentation of cytomegalovirus infection. Eur J Gastroenterol Hepatol. 2006;18:443-445.

40. Condat B, Pessione F, Hillaire S, et al. Current outcome of portal vein thrombosis in adults: risk and benefit of anticoagulant ther apy. Gastroenterology. 2001;120:490-497.

41. Poultsides GA, Lewis WC, Feld R, Walters DL, Cherry DA, Ruby ST. Portal vein thrombosis after laparoscopic colectomy: thrombolytic therapy via the superior mesenteric vein. Am Surg. 2005;71:856-860.

42. Bernades P, Baetz A, Lévy P, Belghiti J, Menu Y, Fékété F. Splenic and portal venous obstruction in chronic pancreatitis. A prospective longitudinal study of a medical-surgical series of 266 patients. Dig Dis Sci. 1992;37:340-346.

43. Fujita F, Lyass S, Otsuka K, et al. Portal vein thrombosis following splenectomy: identification of risk factors. Am Surg. 2003;69:951-956.

44. Bick RL. Coagulation abnormalities in malignancy: a review. Semin Thromb Hemost. 1992;18:353-372.

45. Plessier A, Darwish-Murad S, Hernandez-Guerra M, et al. Acute portal vein thrombosis unrelated to cirrhosis: a prospective multicenter follow-up study. Hepatology. 2010;51:210-218.

46. Habu D, Nishiguchi S, Shiomi S, et al. Portal vein thrombosis following percutaneous ethanol injection therapy for hepatocellular carcinoma. Indian J Gastroenterol. 2002;21:162-163.

47. Zheng RQ, Kudo M, Inui K, et al. Transient portal vein thrombosis caused by radiofrequency ablation for hepatocellular carcinoma. J Gastroenterol. 2003;38:101-103.

48. Matsumoto K, Yamao K, Ohashi K, et al. Acute portal vein thrombosis after EUS-guided FNA of pancreatic cancer: case report. Gastrointest Endosc. 2003;57:269-271.

49. Langnas AN, Marujo W, Stratta RJ, Wood RP, Shaw Jr BW. Vascular complications after orthotopic liver transplantation. Am J Surg. 1991;161:76-82.

50. Doria C, Marino IR. Acute portal vein thrombosis secondary to donor/recipient portal vein diameter mismatch after orthotopic liver transplantation: a case report. Int Surg. 2003:88:184-187.

51. Dörffel T, Wruck T, Rückert RI, Romaniuk P, Dörffel Q, Wermke W. Vascular complications in acute pancreatitis assessed by color duplex ultrasonography. Pancreas. 2000;21:126-133.

52. Murad SD, Valla DC, de Groen PC, et al. Pathogenesis and treatment of Budd-Chiari syndrome combined with portal vein thrombosis. Am J Gastroenterol. 2006;101:83-90.

53. Anand AC, Sashindran VK, Mohan L. Gastrointestinal problems at high altitude. Trop Gastroenterol. 2006;27:147-153.

54. Yadav S, Dutta AK, Sarin SK. Do umbilical vein catheterization and sepsis lead to portal vein thrombosis? A prospective, clinical, and sonographic evaluation. I Pediatr Gastroenterol Nutr. 1993;17:392-396.

55. Sakha SH, Rafeey M, Tarzamani MK. Portal venous thrombosis after umbilical vein catheterization. Indian J Gastroenterol. 2007;26:283-284.

56. Giraudo G, Greget M, Oussoultzoglou E, Rosso E, Bachellier P, Jaeck D. Preoperative contralateral portal vein embolisation before major hepatic resection is a safe and efficient procedure: a large single institution experience. Surgery. 2008;143:476-482.

57. Stringer MD, Heaton ND, Karani J, et al. Patterns of portal vein occlusion and their etiological significance. $\mathrm{Br} J$ Surg. 1994;81:1328-1331.

58. Odievre M, Pige G, Alagille D. Congenital abnormalities associated with extraheptic portal hypertension. Arch Dis Child. 1977;52:383-385.

59. Pinto RB, Silveira TR, Bandenilli E, Rohsig L. Portal vein thrombosis in children and adolescents: the low prevalence of 
hereditary thrombophilic disorders. I Pediatr Surg. 2004;39:1356-1361.

60. Amitrano L, Brancaccio V, Guardascione MA, Margaglione M, lannaccone L, D'Andrea G. Inherited coagulation disorders in cirrhotic patients with portal vein thrombosis. Hepatology. 2000;31:345-348.

61. Mangia A, Villani MR, Cappucci G, et al. Causes of portal venous thrombosis in cirrhotic patients: the role of genetic and acquired factors. Eur J Gastroenterol Hepatol. 2005;17:745-751.

62. Erkan O, Bozdayi AM, Disibeyaz S, Oguz D, Ozcan M, Bahar K. Thrombophilic gene mutations in cirrhotic patients with portal vein thrombosis. Eur J Gastroenterol Hepatol. 2005;17:339-343.

63. Zocco MA, Di Stasio E, De Cristofaro R, et al. Thrombotic risk factors in patients with liver cirrhosis: correlation with MELD scoring system and portal vein thrombosis development. J Hepatol. 2009;51:682-689.

64. Maruyama H, Okugawa H, Takahashi M, Yokosuka O. De novo portal vein thrombosis in virus-related cirrhosis: predictive factors and long-term outcomes. Am J Gastroenterol. 2013;108:568574.

65. Amitrano L, Brancaccio V, Guardascione MA, et al. Portal vein thrombosis after variceal endoscopic sclerotherapy in cirrhotic patients: role of genetic thrombophilia. Endoscopy. 2002;34:535538.

66. Malkowski P, Pawlak J, Michalowicz B, Szczerban J, Wroblewski T, Leowska E. Thrombolytic treatment of portal thrombosis. Hepatogastroenterology. 2003;50:2098-2100.

67. Poddar U, Thapa BR, Rao KL, Singh K. Etiological spectrum of esophageal varices due to portal hypertension in Indian children: is it different from the West? J Gastroenterol Hepatol. 2008;23:1354-1357.

68. Valla DC, Condat B, Lebrec D. Spectrum of portal vein thrombosis in the West. J Gastroenterol Hepatol. 2002:17:S224-S227.

69. Rangari M, Gupta R, Jain M, Malhotra V, Sarin SK. Hepatic dysfunction in patients with extrahepatic portal venous obstruction. Liver Int. 2003;23:434-439.

70. Arora NK, Lodha R, Gulati S, et al. Portal hypertension in north Indian children. Indian J Pediatr. 1998;65:585-591.

71. Mehrotra RN, Batia V, Dabadghao P, Yachha SK. Extrahepatic portal vein obstruction in children: anthropometry, growth hormone, and insulin-like growth factor I. J Pediatr Gastroenterol Nutr. 1997;25:520-523.

72. Nihal N, Bapat MR, Rathi P, et al. Relation of insulin like growth factor-1 and insulin-like growth factor binding protein-3 levels to growth retardation in extrahepatic portal vein obstruction. Hepatol Int. 2009;3:305-309.

73. Ganguly S, Sarin SK, Bhatia V, Lahoti D. The prevalence and spectrum of colonic lesions in patients with cirrhotic and noncirrhotic portal hypertension. Hepatology. 1995;21:1226-1231.

74. Chawla Y, Dilawari JB. Gall Bladder varices in portal vein thrombosis. AJR. 1994;162:643-645.

75. de Ville de Goyet J, Alberti D, Falchetti D, et al. Treatment of extrahepatic portal hypertension in children by mesenteric-to-left portal vein bypass: a new physiological procedure. Eur J Surg. 1999;165:777-781.

76. Bellomo-Brandao MA, Morcillo AM, Hessel G, Cardoso SR, Servidoni Mde F, da Corta Pinto EA. Growth assessment in children with extrahepatic portal vein obstruction and portal hypertension. Ar Gastro. 2003;40:247-250.

77. Minguez B, Garcia-Pagan JC, Bosch J, et al. Noncirrhotic portal vein thrombosis exhibits neuropsychological and MR changes consistent with minimal hepatic encephalopathy. Hepatology. 2006;43:707-714.

78. Dilawari JB, Chawla Y. Pseudoscleoring cholangitis in extrahepatic portal venous obstruction. Gut. 1992;33:272-276.
79. Khuroo MS, Yattoo GN, Zasyar SA, et al. Biliary abnormalities associated with extrahepatic portal venous obstruction. Hepatology. 1993;17:807-813.

80. Dhiman RK, Puri D, Chawla Y, et al. Biliary changes in extrahepatic portal venous obstruction compression by collaterals or ischemia? Gastrointest Endosc. 1999;50:646-652.

81. Condat B, Vilgram V, Asselak T, et al. Portal cavernoma associated cholangiopathy a clinical and MR cholangiography coupled with MR portography imaging study. Hepatology. 2003:37:1302-1308.

82. Malkhan GH, Bhatia ST, Bastin K, et al. Cholangiography associated with portal hypertension diagnostic evaluation and clinical implications. Gastroint Endos. 1999;49:344-348.

83. Sezgin O, Oguz D, Attritas E, Saritas U, Sahin B. Endoscopic management of biliary obstruction carried by cavernous transformation of portal vein. Gastroint Endos. 2003;58:602-608.

84. Kocher G, Himmelmann A. Portal vein thrombosis (PVT): a study of 20 non-cirrhotic cases. Swiss Med Wkly. 2005;135:372-376.

85. Kobayashi S, Ng CS, Kazama T, et al. Hemodynamic and morphological changes after portal vein embolisation: different efforts central and peripheral zones in the liver on multiphasic computed tomography. J Comput Assist Tomog. 2004;28:804-810.

86. Vilgrain V, Condat B, Bureau C, et al. Atrophy-hypertrophy complex in patients with cavernous transformation of the portal vein: CT evaluation. Radiology. 2006;241:149-155.

87. Bilodeau M, Aubry MC, Houle R, Burnes PN, Ethier C. Evaluation of hepatocytes injury following partial ligation of the left portal vein. J Hepatol. 1999;30:29-37.

88. Van Gansbeke D, Avni EF, Delcour C, Engelholm L, Struyven J. Sonographic features of portal vein thrombosis. AJR Am J Roentgenol. 1985;144:749-752.

89. Wang JT, Zhao HY, Liu YL. Portal vein thrombosis. Hepatobiliary Pancreat Dis Int. 2005:4:515-518.

90. Tessler FN, Gehring BJ, Gomes AS, et al. Diagnosis of portal vein thrombosis: value of color Doppler imaging. AJR Am J Roentgenol. 1991;157:293-296.

91. Parvey HR, Eisenberg RL, Giyanani V, Krebs CA. Duplex sonography of the portal venous system: pitfalls and limitations. Am J Roentgenol. 1989;152:765-770.

92. Lai L, Brugge WR. Endoscopic ultrasound is a sensitive and specific test to diagnose portal venous system thrombosis (PVST). Am J Gastroenterol. 2004;99:40-44.

93. Palazzo I, Hochain P, Helmer C, et al. Biliary varices on endoscopic ultrasonography: clinical presentation ad outcome. Endoscopy. 2000;32:520-524.

94. Umpheren JL, Pecha RE, Urayama S. Biliary stricture caused by portal biliopathy. Diagnosis by EUS with Doppler US. Gastrointest Endosc. 2004;60:1021-1024.

95. Chawla A, Dewan R, Sarin SK. The frequency and influence of gall bladder varices on gall bladder function in patients with portal hypertension. Am J Gastroenterol. 1995;90:2011-2014.

96. Parvey HR, Raval B, Sandler CM. Portal vein thrombosis: imaging findings. Am J Roentgenol. 1994;162:77-81.

97. Lee HK, Park SJ, Yi BH, Yeon EK, Kim JH, Hong HS. Portal vein thrombosis: CT features. Abdom Imaging. 2008;33:72-79.

98. Shah TU, Semelka RC, Voultsinos V, et al. Accuracy of magnetic resonance imaging for preoperative detection of portal vein thrombosis in liver transplant candidates. Liver Transpl. 2006;12:1682-1688.

99. Cakmak O, Elmas N, Tamsel S, et al. Role of contrast-enhanced 3D magnetic resonance portography in evaluating portal venous system compared with color Doppler ultrasonography. Abdom Imaging. 2008;33:65-71.

100. Smith CS, Sheehy N, McEniff N, Keogan MT. Magnetic resonance portal venography: use of fast-acquisition true FISP imaging in the 
detection of portal vein thrombosis. Clin Radiol. 2007;62:11801188.

101. Lin J, Zhou KR, Chen ZW, Wang JH, Wu ZQ, Fan J. Three-dimensional contrast-enhanced MR angiography in diagnosis of portal vein involvement by hepatic tumors. World I Gastroenterol. 2003;9:1114-1118.

102. Glockner JF, Forauer AR, Solomon H, Varma CR, Perman WH. Three-dimensional gadolinium enhanced MR angiography of vascular complications after liver transplantation. Am J Roentgenol. 2000;174:1447-1453.

103. Vlachogiannakos J, Patch D, Watkinson A, Tibballs J, Burroughs AK. Carbon-dioxide portography: an expanding role? Lancet. 2000;355:987-988.

104. Kreft B, Strunk H, Flacke S, et al. Detection of thrombosis in the portal venous system: comparison of contrast-enhanced MR angiography with intraarterial digital subtraction angiography. Radiology. 2000;216:86-92.

105. Sun L, Guan YS, Pan WM, et al. Highly metabolic thrombus of the portal vein: $18 \mathrm{~F}$ fluorodeoxyglucose positron emission tomography/computer tomography demonstration and clinical significance in hepatocellular carcinoma. World J Gastroenterol. 2008;14:1212-1217.

106. Dilawari JB, Chawla YK, Raju GS, Kaur U, Bambery P. Splenoportovenography in portal hypertension: a safe outpatient procedure. Can Assoc Radiol J. 1990;41:146-148.

107. Sarin SK, Lahoti D, Saxena SP, Murthy NS, Makwana UK. Prevalence, classification and natural history of gastric varices: a long-term follow up study in 568 portal hypertension patients. Hepatology. 1992;16:1343-1349.

108. Webster GJ, Burroughs AK, Riordan SM. Review article: portal vein thrombosis - new insights into aetiology and management. Aliment Pharmacol Ther. 2005;21:1-9.

109. DeLeve LD, Valla DC, Garcia-Tsao G. Vascular disorders of the liver. Hepatology. 2009;49:1729-1764.

110. Baril N, Wren S, Radin R, Ralla P, Stain S. The role of anticoagulation in pylephlebitis. Am J Surg. 1996;172:449-452.

111. Condat B, Pessine T, Helene DM, Hillaire S, Valla D. Recent portal or mesenteric venous thrombosis, increased recognition and frequent recanalisation on anticoagulant therapy. Hepatology. 2000;32:466-470.

112. Kumar S, Sarr MG, Kamath PS. Mesenteric venous thrombosis. N Engl J Med. 2001;345:1683-1688.

113. Voorhees Jr AB, Price Jr JB. Extrahepatic portal hypertension. A retrospective analysis of 127 cases and associated clinical implications. Arch Surg. 1974;108:338-341.

114. Amitrano L, Guardascione MA, Scaglione M, et al. A. Prognostic factors in noncirrhotic patients with splanchnic vein thromboses. Am J Gastroenterol. 2007;102:2464-2470.

115. Thomas $\mathrm{V}$, Jose $\mathrm{T}$, Kumar $\mathrm{S}$. Natural history of bleeding after esophageal variceal eradication in patients with extrahepatic portal venous obstruction; a 20-year follow-up. Indian J Gastroenterol. 2009;28:206-211.

116. Luca A, Caruso S, Milazzo M, et al. Natural course of extrahepatic nonmalignant partial portal vein thrombosis in patients with cirrhosis. Radiology. 2012;265:124-132.

117. Hall TC, Garcea G, Metcalfe M, Bilku D, Dennison AR. Management of acute non cirrhotic non malignant portal vein thrombosis: a systematic review. World J Surg. 2011;35:25102520.

118. Romano F, Caprotti R, Conti M, et al. Thrombosis of the splenoportal axis after splenectomy. Langenbecks Arch Surg. 2006;391:483488.

119. Sheen CL, Lamparelli H, Milne A, Green I, Ramage JK. Clinical features, diagnosis and outcome of acute portal vein thrombosis. Q J Med. 2000;93:531-534.
120. Dolorich LR, Ginsberg JS, Douketis JD, Holbrook AM, Cheah G. A meta analysis comparing low molecular wt heparin with unfractionated heparin in treatment of venous thrombolism examining some unanswered questions regarding location of treatment product use and dosing frequency. Arch Int Med. 2000;160:181-188.

121. Francoz C, Belghiti J, Vilgrain V, et al. Splanchnic vein thrombosis in candidates for liver transplantation: usefulness of screening and anticoagulation. Gut. 2005;54:691-697.

122. Louvet A, Texier F, Dharancy S, et al. Anticoagulation therapy may sense biliary abnormalities due to acute portal thrombosis. Dig Dis Sci. 2006;51:11-17.

123. Spaander MC, Hoekstra J, Hansen BE, Van Buuren $H R$, Leebeek FW, Jansenn HL. Anticoagulant therapy in patients with non-cirrhotic portal vein thrombosis: effect on new thrombotic events and gastrointestinal bleeding. J Thromb Haemost. 2013;11:452-459.

124. Lopeia JE, Correa G, Brazzini A, et al. Percutaneous transhepatic treatment of symptomatic mesenteric venous thrombosis. J Vasc Surg. 2002;36:1058-1067.

125. Aytekin C, Boyvat F, Kurt A, Yologlu Z, Coskun M. Catheter directed thrombolysis with transjugular access in portal vein thrombosis secondary to pancreatitis. Eur J Radiol. 2001;39:80-82.

126. Hollingshead M, Burke CT, Mauro MA, Weeks SM, Dixon RG, Jaques PF. Transcatheter thrombolytic therapy for acute mesenteric and portal vein thrombosis. J Vasc Inter Radiol. 2005;16:651-661.

127. Kercher KW, Sing RF, Watson KW, Matthews BD, LeQuire MH, Heniford BT. Transhepatic thrombolysis in acute portal vein thrombosis after laproscopic splenectomy. Sung Laproso Endo Percutan Tech. 2002;12:131-136.

128. Henao EA, Bohamon WT, Silva Jr MB. Treatment of portal vein thrombosis with relative superior mesenteric artery infusion of recombinant tissue plasminogen activator. I Vase Surg. 2003:38:1411-1415.

129. Tateishi A, Mitsui M, Oki T, et al. Extensive mesenteric vein and portal vein thrombosis significantly treated by thrombosis and anticoagulation. J Gastroenterol Hepatol. 2001;16:1429-1433.

130. Liu FY, Wang MQ, Fan QS, Duan F, Wang ZJ, Song P. Interventional treatment for symptomatic acute-subacute portal and superior mesenteric venous thrombosis. World J Gastro. 2009;15:5028-5034.

131. Wang MQ, Liu FY, Duan F, Wang ZJ, Song P, Fan QS. Acute symptomatic mesenteric venous thrombosis: treatment by catheter directed thrombolysis with transjugular intrahepatic route. Abdom Imaging. 2011;36:390-398.

132. Smalberg JH, Spaander MV, Jie KS, Pattynama PM, van Buuren HR. Risks and benefits of transcatheter thrombolytic therapy in patients with splanchnic venous thrombosis. Thromb Haemost. 2008;100:1084-1088.

133. Fonseca AL, Cleary MA, Cholewczynski W, Sumpio BE, Atweh NA. Omental vein catheter thrombolysis for acute porto-mesenteric vein thrombosis. Ann Vasc Surg. 2013;27, 497.e1-4.

134. Luo J, Yan Z, Wang J, Liu Q, Qu X. Endovascular treatment for nonacute symptomatic portal venous thrombosis through intrahepatic portosystemic shunt approach. I Vasc Interv Radiol. 2011;22:61-69.

135. Uflacher R. Applications of percutaneous mechanical thromboectomy in transjugular intrahepatic portosystemic shunt and portal vein thrombosis. Tech Vas Inter Radiol. 2003;6:59-69.

136. Oğuzkurt P, Tercan F, Ince E, Ezer SS, Hiçsönmez A. Percutaneous treatment of portal vein thrombosis in a child who has undergone splenectomy. J Pediatr Surg. 2008;43:e29-32.

137. Ferro C, Rossi CG, Bovio G, Dahamane M, Centenaro M. Transjugular intrahepatic portosystemic shunt, mechanical aspiration 
thrombectomy, and direct thrombolysis in the treatment of acute portal and superior mesenteric vein thrombosis. Cardiovas Interv Radiol. 2007;30:1070-1074.

138. Adani GL, Baccarani U, Risaliti A, et al. Percutaneous transhepatic portography for the treatment of early portal vein thrombosis after surgery. Cardiovasc Interv Radiol. 2007;30:1222-1226.

139. Amitrano L, Guardascione MA, Menchise A, et al. Safety and efficacy of anticoagulation therapy with low molecular weight heparin for portal vein thrombosis in patients with liver cirrhosis. J Clin Gastroenterol. 2010;44:448-451.

140. Senzolo M, Ferronato C, Burra P, Sartori MT. Anticoagulation for portal vein thrombosis in cirrhotic patients should be always considered. Intern Emerg Med. 2009;4:161-162.

141. Pellicelli AM, Guarascio P, D'Ambrosio C, et al. Portal vein thrombosis in cirrhotic patients: safety and efficacy of low dosage of enoxaparin. J Hepatol. 2010;52:S80.

142. Werner KT, Sando S, Carey EJ, et al. Portal vein thrombosis in patients with end stage liver disease awaiting liver transplantation: outcome of anticoagulation. Dig Dis Sci. 2013;58:1776-1780.

143. Delgado MG, Seijo S, Yepes I, et al. Efficacy and safety of anticoagulation on patients with cirrhosis and portal vein thrombosis. Clin Gastroenterol Hepatol. 2012;10:776-783.

144. Senzolo M, M Sartori T, Rossetto V, et al. Prospective evaluation of anticoagulation and transjugular intrahepatic portosystemic shunt for the management of portal vein thrombosis in cirrhosis. Liver Int. 2012;32:919-927.

145. Martinez M, Tandra A, Vuppalanchi R. Treatment of acute portal vein thrombosis by non-traditional anticoagulation. Hepatology. 2014 Jan 7 http://dx.doi.org/10.1002/hep.26998 [Epub ahead of print].

146. Pannach S, Babatz J, Beyer-Westendorf J. Successful treatment of acute portal vein thrombosis with rivaroxaban. Thromb Haemost. 2013;110:626-627.

147. De Santis A, Moscatelli R, Catalano C, lannetti A, Gigliotti F, Cristofari F. Systemic thrombolysis of portal vein thrombosis in cirrhotic patients: a pilot study. Dig Liver Dis. 2010;42:451455.

148. Villa E, Cammà C, Marietta M, Luongo M, Critelli R, Colopi S. Enoxaparin prevents portal vein thrombosis and liver decompensation in patients with advanced cirrhosis. Gastroenterology. 2012;143:1253-1260.

149. Brearley S, Hawker PC, Dykes PW, Keighley MR. A lethal complication of peripheral vein vasopressin infusion. Hepatogastroenterology. 1985;32:224-225.

150. Celińska-Cedro D, Teisseyre M, Woynarowski M, Socha P, Socha J, Ryzko J. Endoscopic ligation of esophageal varices for prophylaxis of first bleeding in children and adolescents with portal hypertension: preliminary results of a prospective study. J Pediatr Surg. 2003;38:1008-1011.

151. Spaander MC, Murad SD, van Buuren HR, Hansen BE, Kuipers EJ, Janssen HL. Endoscopic treatment of esophagogastric variceal bleeding in patients with noncirrhotic extrahepatic portal vein thrombosis: a long-term follow-up study. Gastrointest Endosc. 2008;67:821-827.

152. Poddar U, Thapa BR, Singh K. Band ligation plus sclerotherapy versus sclerotherapy alone in children with extrahepatic portal venous obstruction. J Clin Gastroenterol. 2005;39:626-629.

153. Dilawari JB, Raju GS, Chawla YK. Development of large splenoadrenorenal shunt after endoscopic sclerotherapy. Gastroenterology. 1989;97:421-426.

154. Orr DW, Harrison PM, Devlin J, et al. Chronic mesenteric venous thrombosis: evaluation and determinants of survival during longterm follow-up. Clin Gastroenterol Hepatol. 2007;5:80-86.

155. Wolff M, Hirner A. Current state of portosystemic shunt surgery. Langenbecks Arch Surg. 2003;388:141-149.
156. Livingstone AS, Koniaris LG, Perez EA, Alvarez N, Levi JU, Hutson DG. 507 Warren-Zeppa distal splenorenal shunts: a 34year experience. Ann Surg. 2006;243:884-892.

157. Sharma BC, Singh RP, Chawla YK, et al. Effect of shunt surgery on spleen size, portal pressure and oesophageal varices in patients with non-cirrhotic portal hypertension. J Gastroenterol Hepatol. 1997;12:582-584.

158. Dasgupta R, Roberts E, Superina RA, Kim PC. Effectiveness of Rex shunt in the treatment of portal hypertension. I Pediatr Surg. 2006;41:108-112.

159. Krebs-Schmitt D, Briem-Richter A, Grabhorn E, et al. Effectiveness of Rex shunt in children with portal hypertension following liver transplantation or with primary portal hypertension. Pediatr Transpl. 2009;13:540-544.

160. Query JA, Sandler AD, Sharp WJ. Use of autogenous saphenous vein as a conduit for mesenterico-left portal vein bypass. J Pediatr Surg. 2007;42:1137-1140.

161. Kim HB, Pomposelli JJ, Lillehei CW, et al. Mesogonadal shunts for extrahepatic portal vein thrombosis and variceal hemorrhage. Liver Transpl. 2005;11:1389-1394.

162. Shaw Jr BW, Iwatsuki S, Bron K, Starzl TE. Portal vein grafts in hepatic transplantation. Surg Gynecol Obstet. 1985;161:6668.

163. Hoekstra J, Seijo S, Rautou PE, et al. Pregnancy in women with portal vein thrombosis: results of a multicentric European study on maternal and fetal management and outcome. J Hepatol. 2012;57:1214-1219.

164. Francoz C, Valla D, Durand F. Portal vein thrombosis, cirrhosis, and liver transplantation. J Hepatol. 2012;57:203-212.

165. Bilbao Jl, Elorz M, Vivas I, Martínez-Cuesta A, Bastarrika G, Benito A. Transjugular intrahepatic portosystemic shunt (TIPS) in the treatment of venous symptomatic chronic portal thrombosis in non-cirrhotic patients. Cardiovasc Interv Radiol. 2004;27:474-480.

166. Van Ha TG, Hodge J, Funaki B, et al. Transjugular intrahepatic portosystemic shunt placement in patients with cirrhosis and concomitant portal vein thrombosis. Cardiovasc Interv Radiol. 2006:29:785-790.

167. Superina R, Shneider B, Emre S, Sarin S, de Ville de Goyet J. Surgical guidelines for the management of extra-hepatic portal vein obstruction. Pediatr Transpl. 2006;10:908-913.

168. Luo X, Nie L, Zhou B, et al. Transjugular intrahepatic portosystemic shunt for the treatment of portal hypertension in noncirrhotic patients with portal cavernoma. Gastroenterol Res Pract. 2014;2014:659726. http://dx.doi.org/10.1155/2014/ 659726.

169. Qi X, Han G, Yin Z, et al. Transjugular intrahepatic portosystemic shunt for portal cavernoma with symptomatic portal hypertension in non-cirrhotic patients. Dig Dis Sci. 2012;57:1072-1082.

170. Han G, Qi X, He C, et al. Transjugular intrahepatic portosystemic shunt for portal vein thrombosis with symptomatic portal hypertension in liver cirrhosis. J Hepatol. 2011;54:78-88.

171. Fanelli F, Angeloni S, Salvatori FM, et al. Transjugular intrahepatic portosystemic shunt with expanded-polytetrafuoroethylenecovered stents in non-cirrhotic patients with portal cavernoma. Dig Liver Dis. 2011;43:78-84.

172. Lladó L, Fabregat J, Castellote J, et al. Management of portal vein thrombosis in liver transplantation: influence on morbidity and mortality. Clin Transpl. 2007;2:716-721.

173. Lendoire J, Raffin G, Cejas N, et al. Liver transplantation in adult patients with portal vein thrombosis: risk factors, management and outcome. HPB (Oxford). 2007;9:352-356.

174. Harmanci O, Bayraktar Y. Portal hypertension due to portal venous thrombosis: etiology, clinical outcomes. World J Gastroenterol. 2007;13:2535-2540. 
175. Yerdel MA, Gunson B, Mirza D, etal. Portal vein thrombosis in adults undergoing liver transplantation: risk factors, screening, management and outcome. Transplantation. 2000;69:1873-1881.

176. Rodriguez-Castro KI, Porte RJ, Nadal E, Germani G, Burra P, Senzolo M. Management of non neoplastic portal vein thrombosis in the setting of liver transplantation: a systematic review. Transplantation. 2012;94:1145-1153.

177. Tao YF, Teng F, Wang ZX, et al. Liver transplant recipients with portal vein thrombosis: a single center retrospective study. Hepatobiliary Pancreat Dis Int. 2009;8:34-39.

178. Doenecke A, Tsui TY, Zuelke C, et al. Pre-existent portal vein thrombosis in liver transplantation: influence of pre-operative disease severity. Clin Transpl. 2010;24:48-55.

179. Hajdu CH, Murakami T, Diflo T, et al. Intrahepatic portal cavernoma as an indication for liver transplantation. Liver Transpl. 2007;13:1312-1316.

180. Connolly GC, Chen R, Hyrien O, et al. Incidence, risk factors and consequences of portal vein and systemic thromboses in hepatocellular carcinoma. Thromb Res. 2008;122:299-306.

181. D'Amico M, Pasta L, Sammarco P. MTHFR C677TT, PAl1 4G-4G, V Leiden Q506, and prothrombin G20210A in hepatocellular carcinoma with and without portal vein thrombosis. J Thromb Thrombolysis. 2009;28:70-73.

182. Carr BI, Buch SC, Kondragunta V, Pancoska P, Branch RA. Tumor and liver determinants of prognosis in unresectable hepatocellular carcinoma: a case cohort study. J Gastroenterol Hepatol. 2008;23:1259-1266.

183. Rossi S, Rosa L, Ravetta V, et al. Contrast-enhanced versus conventional and color Doppler sonography for the detection of throm- bosis of the portal and hepatic venous systems. Am J Roentgenol. 2006;186:763-773.

184. Rossi S, Ghittoni G, Ravetta V, et al. Contrast-enhanced ultrasonography and spiral computed tomography in the detection and characterization of portal vein thrombosis complicating hepatocellular carcinoma. Eur Radiol. 2008;18:1749-1756.

185. Neeman Z, Libutti SK, Patti JW, Wood BJ. Percutaneous radiofrequency ablation of hepatocellular carcinoma in the presence of portal vein thrombosis. Clin Imaging. 2003;27:417-420.

186. Salem R, Lewandowski R, Roberts C, et al. Use of yttrium-90 glass microspheres (TheraSphere) for the treatment of unresectable hepatocellular carcinoma in patients with portal vein thrombosis. J Vasc Interv Radiol. 2004;15:335-345.

187. Kulik LM, Carr BI, Mulcahy MF, et al. Safety and efficacy of $90 Y$ radiotherapy for hepatocellular carcinoma with and without portal vein thrombosis. Hepatology. 2008;47:71-81.

188. Sotiropoulos GC, Radtke A, Schmitz KJ, et al. Liver transplantation in the setting of hepatocellular carcinoma and portal vein thrombosis: a challenging dilemma? Dig Dis Sci. 2008;53:1994-1999.

189. Huang YJ, Hsu HC, Wang $\mathrm{CY}$, et al. The treatment responses in cases of radiation therapy to portal vein thrombosis in advanced hepatocellular carcinoma. Int I Radiat Oncol Biol Phys. 2009;73:1155-1163.

190. Mazzaferro V, Sposito C, Bhoori S, et al. Ytterium-90 radioembolization for intermediate-advanced hepatocellular carcinoma: a phase 2 study. Hepatology. 2013;57:1826-1837. 